\title{
AN EVALUATION OF THE UTILITY OF \\ A WHALE WATCHING CODE OF CONDUCT
}

\author{
by \\ Greig Gjerdalen \\ B.A. Simon Fraser University, 1984
}

RESEARCH PROJECT SUBMTTTED IN PARTIAL FULFILLMENT OF THE REQUIREMENTS FOR THE DEGREE OF MASTER OF NATURAL RESOURCES MANAGEMENT in the

School of Resource and Environmental Management Report No 206

\author{
(C) Greig Gjerdalen 1997 \\ SIMON FRASER UNIVERSITY
}

August 1997

All rights reserved. This work may not be reproduced in whole or in part, by photocopy or other means, without the permission of the author. 
National Library

of Canada

Acquisitions and

Bibliographic Services

395 Wellington Street

Ottawa ON K1A ONA

Canada
Bibliothèque nationale

du Canada

Acquisitions et

services bibliographiques

395, rue Wellington

Ottawa ON K1A ON4

Canada
The author has granted a nonexclusive licence allowing the National Library of Canada to reproduce, loan, distribute or sell copies of this thesis in microform, paper or electronic formats.

The author retains ownership of the copyright in this thesis. Neither the thesis nor substantial extracts from it may be printed or otherwise reproduced without the author's permission.
L'auteur a accordé une licence non exclusive permettant à la Bibliothèque nationale du Canada de reproduire, prêter, distribuer ou vendre des copies de cette thèse sous la forme de microfiche/film, de reproduction sur papier ou sur format électronique.

L'auteur conserve la propriété du droit d'auteur qui protège cette thèse. $\mathrm{Ni}$ la thèse ni des extraits substantiels de celle-ci ne doivent être imprimés ou autrement reproduits sans son autorisation. 


\begin{abstract}
The purpose of this study is to evaluate the utility of a code of conduct in helping Johnstone Strait whale watching operators conduct their environmental stewardship roles. Specific objectives are to evaluate the utility of the Johnstone Strait code of conduct in encouraging compliance to agreed upon guidelines, and to determine the most effective methods of encouraging such behavior.
\end{abstract}

This research draws upon existing literature to establish criteria for assessing the utility of a code of conduct. The code of conduct was developed by the commercial whale watching operators of Johnstone Strait, British Columbia in conjunction with researchers at the Centre for Tourism Policy and Research, Simon Fraser University. The research then uses a survey instrument to assess operator perceptions' concerning the utility of the code of conduct in encouraging compliance with agreed upon stewardship guidelines. The survey results suggest that the code of conduct is more effective than government regulations in encouraging operators to follow whale watching code guidelines. As well, the findings indicate that the code is very effective in helping operators communicate with each other, and encourage them to implement conservation practices in their operations. 


\section{ACKNOWLEDGEMENTS}

I wish to sincerely thank Dr. Peter Williams who has been a source of continued support and advice. His expertise has both challenged and helped me.

Thank you Dr. Alison Gill for your warm encouragement and guidance during my studies at R.E.M.

Thank you Hannele, Luke and Cole for your patience, support and love. You have been an inspiration for life itself and provided balance through the research and writing of this project.

I wish to thank my mom and dad who have always encouraged, nurtured and supported the directions I have chosen to take.

Thanks to the wild orcas whose grace, power and intelligence provided the inspiration for this work. 


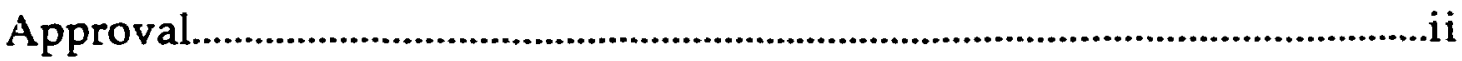

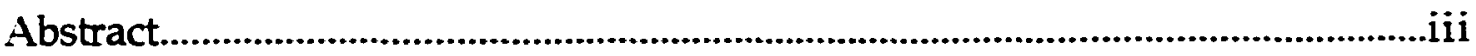

Acknowledgments....................................................................................................

Table of Contents ................................................................................................

List of Tables.....................................................................................................................

List of Figures...............................................................................................................

List of Acronyms Used.........................................................................................

List of Appendices.........................................................................................................

CHAPTER ONE: INTRODUCTION

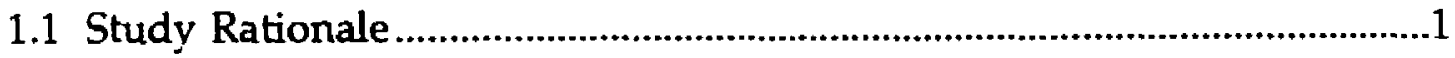

1.2 Purpose of Study and Research Questions ..................................................4

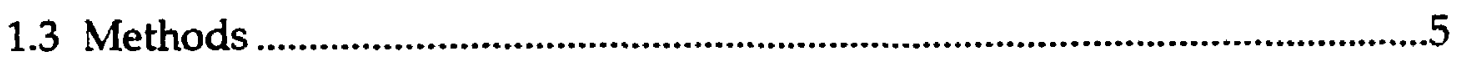

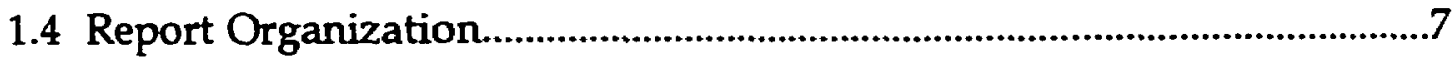

CHAPTER TWO: REVIEW OF LITERATURE AND EXISTING LEGISLATION

2.1 Rationale and Organization ........................................................................

2.2 Managing Common Property Resources...................................................... 
2.2.1 Resource management and the tragedy of the commons .9

2.3 Current Legislation Regarding Marine Environmental Management .13

2.3.1 Legislated systems in marine environments .................................14

2.3.2 International legislated cases........................................................16

2.3.3 Pitfalls of Legislated Approaches....................................................19

2.3.4 Orca culture ........................................................................................20

2.4 The Role of Voluntary Compliance Systems ...............................................23

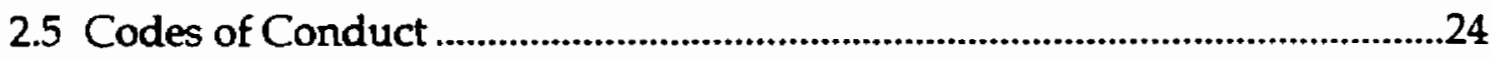

2.5.1 Benefits of self-regulation...............................................................25

2.5.2 Community-based stewardship ....................................................27

2.5.3 Human capital ..............................................................................28

2.5.4 Critical code content........................................................................31

2.6 Compliance to Societal Norms...........................................................................33

2.6.1 Prosocial behavior and natural resource protection.....................33

2.6.2 The role of social norms...................................................................34

2.6.3 Reasons for normative violations...................................................36

2.6.4 Deterrence models...............................................................................39

2.6.5 Perceived risk of social condemnation as punishment ..............41 


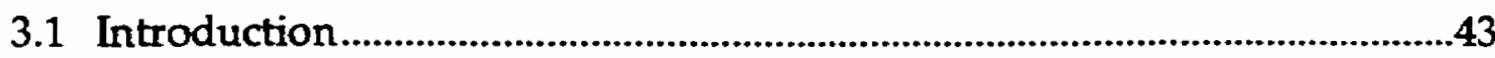

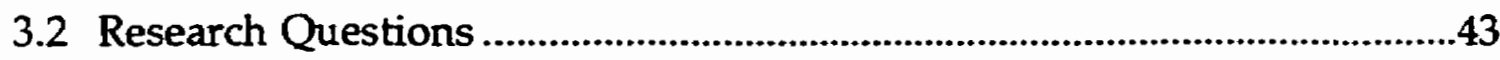

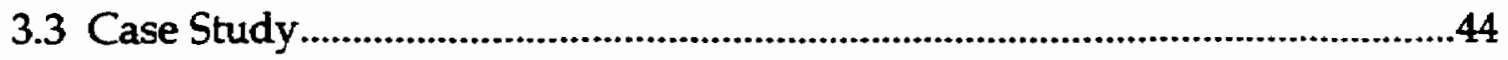

3.3.1 Description of the case study area....................................................45

3.3.2 Data Collection .............................................................................47

3.3.3 Compliance Survey ........................................................................48

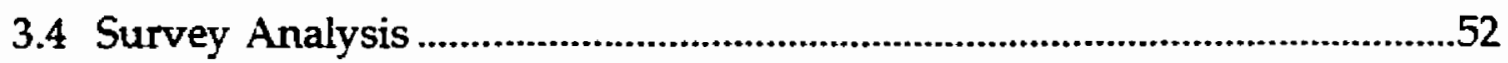

CHAPTER FOUR: FINDINGS

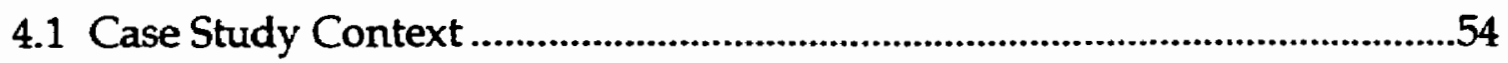

4.2 Development of the Code of Conduct.........................................................55

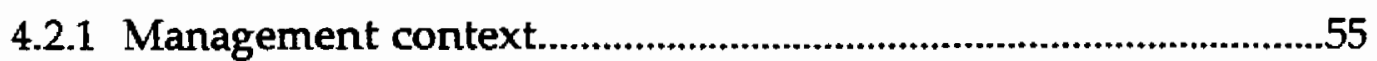

4.2.2 Code development process............................................................57

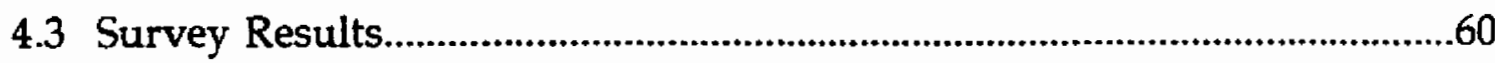

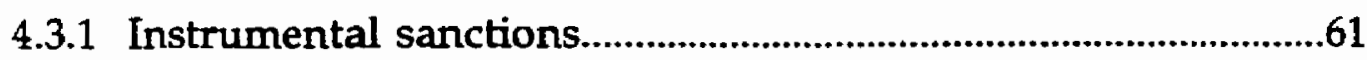

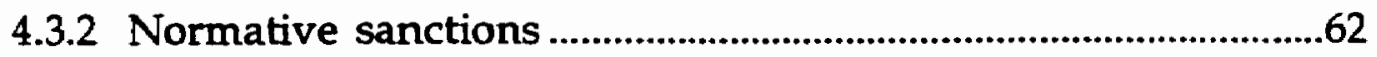

4.3.3 Beliefs and perceptions toward code guidelines ...........................64

4.3.4 The efficacy of the code guidelines in encouraging environmental stewardship..............................................................65

4.3.5 The efficacy of the code guidelines in achieving environmental stewardship. 
4.4.1 Perceived sanctions and compliance. .69

4.4.2 Beliefs and perceptions toward code guidelines . .72

4.4.3 The efficacy of the code guidelines in encouraging environmental stewardship . .73

CHAPTER FIVE: MANAGEMENT IMPLICATIONS

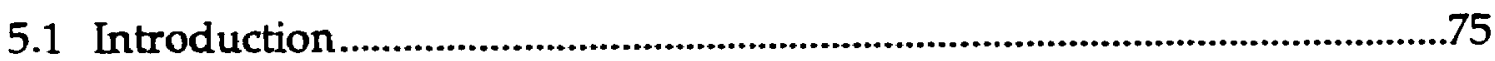

5.2 The Role of Voluntary Compliance Systems ..............................................77

5.2.1 Managing common property resources ...........................................78

5.2.2 Compliance to social norms.............................................................79

5.2.3 Commercial operators' role as educator and role model............80

5.2.4 Educational tool for new operators................................................82

5.2.5 Educational tool for visitors...........................................................82

5.3 Shared Evaluation and Monitoring …........................................................84

CHAPTER SIX: CONCLUSIONS AND RECOMMENDATIONS FOR FURTHER RESEARCH

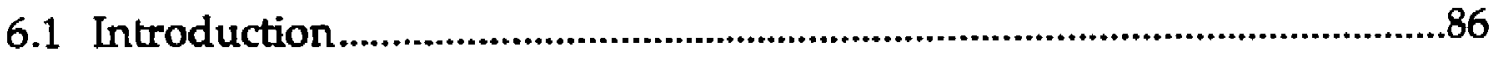

6.2 Summary of Major Findings..........................................................................86

6.3 Recommendations for Further Research ....................................................87

6.3.1 Encouragement of a commitment to the development of a code of conduct ..........................................................................................8

6.3.2 Identification of indicators of compliance.......................................8 
6.3.3 Development of criteria for code success.......................................8.

6.3.4 Establishment of evaluation and monitoring...............................89

6.3.5 Evaluation of the code by other stakeholders............................89

APPENDICES

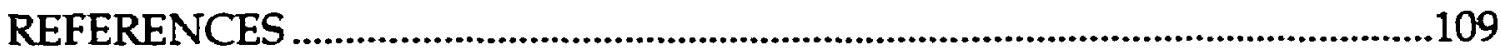




\section{LIST OF TABLES}

4.1 Code Development Framework

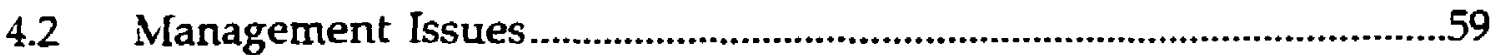

4.3 Comparative Effectiveness of Different Types of Sanctions.................62

4.4 Perceived Certainty of Punishment..........................................................62

4.5 Perceived Severity of Self-Imposed Sanctions ...........................................63

4.6 Comparative Importance of Beliefs and Perceptions..............................65

4.7 Efficacy in Encouraging Environmental Stewardship..........................67

4.8 Efficacy in Achieving Environmental Stewardship ..............................68

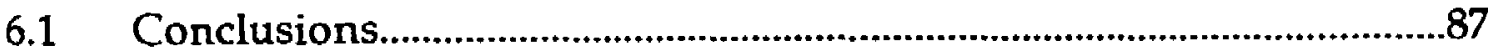




\section{LIST OF FIGURES}

2.1 Map of Johnstone Strait and Robson Bight

(Michael Bigg) Ecological Reserve.

4.1 Map of Southern Inside Passage B.C . ............................................................56

5.1 Environmental Stewardship Framework ...............................................76 


\section{LIST OF ACRONYMS USED}

$\mathrm{BC}$

British Columbia

DFO

Department of Fisheries and Oceans

$\mathrm{GH} / \mathrm{SM}$

Gwaii Haanas/South Moresby

JS

Johnstone Strait

JSKWC

Johnstone Strait Killer Whale Committee

BCMOELP

British Columbia Ministry of Environment, Lands, and Parks

NMFS

National Marine Fisheries Service

RBMBER

Robson Bight (Michael Bigg) Ecological Reserve

UNEP

United Nations Environment Programme 


\section{LIST OF APPENDICES}

Appendix 1 Johnstone Strait Code of Conduct.................................................90

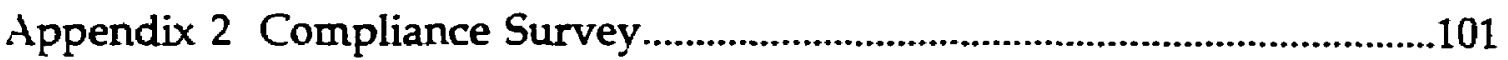




\section{CHAPTER ONE: INTRODUCTION}

\subsection{STUDY RATIONALE}

As one of the world's largest and fastest growing industries (World Travel and Tourism Council, 1993), tourism faces the challenge of maintaining economic growth while sustaining the natural environment upon which it depends. The tourism industry utilizes the environment as its primary resource base, and its environmental impact has been widely recognized in the tourism literature (Butler, 1989; Inskeep, 1989; McKercher, 1992).

Marine ecosystems provide human society with a wealth of economic resources and a source of outstanding recreation and tourism opportunities. In many areas of the world, marine habitats are being threatened by a variety of human activities including tourism. Many portions of British Columbia's coastal waters provide outstanding habitat for large populations of Orcinus orca, or killer whales as they are commonly known. Some of these habitats have become popular locations for commercial whale watching tour operations. Unfortunately, existing government jurisdiction and legislation regarding the stewardship of these ecologically sensitive areas and the whales that use them is complex and at times unclear. This has resulted in a haphazard approach to public management of these valuable assets. 
Potentially valuable management tools for improving environmental practices in a variety of tourism settings are self-imposed codes of conduct. Such codes are written documents outlining specific guidelines of behavior for defined groups of stakeholders. Typically these codes build common understanding amongst stakeholders about the self-regulating guidelines to be followed in varying operational situations (Arrow, 1979; ARA Consulting Group, 1991; Duffus and Ford, 1995). They can also provide a platform for communication amongst stakeholders on issues of common concern (Anderson, 1986). This provides an opportunity to avoid or resolve conflicts, and stimulate the development of effective self-enforced management strategies (Kaza, 1988; Rolston III, 1988).

Whale watching codes of conduct are complements to traditional legislated management systems. They can potentially help conserve orcas and their habitats, thereby protecting the basis for a more sustainable industry.

On a global scale, the impact of commercial whale watching activities on whales is the subject of considerable debate (Atkins and Shwartz, 1988; Briggs, 1991; National Marine Fisheries Service, 1992; Franklin, 1995). Although whale watching appears to be a fairly benign use of the marine environment, especially when compared to the extractive industries of commercial and sport fishing, the growing interest in whale watching can lead to the 
environmental degradation of orca habitat (Blood and MacAskie, 1988).

Disturbance of whales, as well as other wildlife and natural habitats, by boats and tourists have been associated with whale watching activities (Duffus, 1987; Briggs, 1988; JSKWC, 1991).

In British Columbia, pressure for change in the management/stewardship of orca habitat comes from federal and provincial government agencies, British Columbia Ministry of Environment, Lands \& Parks (BCMOELP), and the federal Department of Fisheries and Oceans (DFO), as well as, whale researchers and commercial whale watching operators (Darling, 1986; Henwood, 1988; JSKWC, 1991).

Stakeholders in the whale watching community are being compelled to act responsibly. The public has become more knowledgeable of environmental risk, less tolerant of environmental degradation, and more demanding in its expectations of those responsible for the management of these marine assets. They demand regulation and enforcement of guidelines designed to protect the natural resource base (Beeler and Wood, 1990). As a consequence, improved environmental management of whale watching operations can be viewed as an opportunity for such nature-based tourism businesses to not only better their image through sound environmental practices (Budzick, 1992; Surma, 1992), but more importantly to guide their operations towards a more sustainable future (UNEP, 1993). 


\subsection{PURPOSE OF STUDY AND RESEARCH QUESTIONS}

The overall purpose of this research is to evaluate the utility of a code of conduct in helping Johnstone Strait whale watching operators conduct their environmental stewardship roles.

Main Research Questions

Within the context of evaluating the utility of a code of conduct, the applied research questions addressed are:

(1) How has the Johnstone Strait whale watching code been useful to operators?

(2) How does a code of conduct encourage compliance to agreed upon guidelines?

(3) What are the most effective methods of encouraging compliance?

1

\subsection{METHODS}

This study used both primary and secondary research techniques in addressing the research questions. It included a literature review and case study. 
A literature review was carried out in order to develop criteria for assessing the utility of the Johnstone Strait code of conduct. In particular, five areas of the literature were explored. The review of the literature on common property resource theory, as it applies to conventional resource management, sets the context for the study. The review of marine ecological management legislation examines the elements of regulatory and self-regulatory approaches to resource management in the context of local and international marine cases. The third section investigates some of the major strengths and weaknesses associated with conventional approaches to marine ecological management. The codes of conduct literature is used to identify the components and potential benefits of self-regulatory approaches to managing common property resources. This is followed by a discussion of the literature associated with why people comply with social norms. It is intended to provide insight into why people would, or would not follow the guidelines of a code of conduct.

Case Study

Based on the findings of the literature review, a case study was undertaken to evaluate the utility of a specific whale watching code of conduct in 
influencing tour operators' behavior. A major component of the case study involved the administration of a questionnaire survey. In particular, the ten major whale watching operators in Johnstone Strait were asked to evaluate the utility of codes of conduct in encouraging compliance to previously accepted whale watching guidelines. Furthermore, since codes of conduct are only useful if tour operators are motivated to improve environmental performance, the survey attempted to identify tour operator motivations for code compliance. The survey instrument design was bounded by assessment criteria that were established through the literature review; personal experiences of the researcher and informal interviews with tour operators. The assessment criteria guided the development of the questions.

\subsection{REPORT ORGANIZATION}

The report is divided into six chapters, including this introduction. Chapter Two reviews the five areas of the literature that are relevant to this study. Chapter Three provides a description of the methods used in the study. A case study approach is used to assess the utility of a code of conduct in encouraging compliance to a set of guidelines. Chapter Four presents the findings of the case study. It describes the development of the Johnstone Strait code of conduct and presents the findings of the compliance survey. The results of the case study are linked to management implications discussed in Chapter Five. The utility of the code is evaluated, and the survey 
findings related to code compliance issues are discussed. Chapter Six concludes with suggestions for further research. 


\subsection{RATIONALE ANDORGANIZATION}

This literature review is divided into five sections. The first section identifies key difficulties in managing common property resources. It highlights the need for new approaches to environmental protection. The second section is concerned with policy and the types of government legislation related to marine ecological management in B.C. and Canada. This is complemented with international examples of regulated and self-regulated approaches to marine environmental management. Some of the major strengths and weaknesses of "command and control" systems in marine settings are investigated in the third section. The fourth section sets the context for assessing the viability of alternative approaches to marine environmental management. It deals with the role of codes of conduct as a potential selfregulatory approach to ecological stewardship. The fifth and final segment of the literature review addresses issues of compliance to voluntary guidelines. It outlines a set of social psychology theory that has relevance to the stewardship of natural resources. 


\subsection{MANAGING COMMON PROPERTY RESOURCES}

For close to three centuries conventional "western management regimes" for natural resources such as wildlife and other "common property resources" have been aimed at avoiding what Hardin (1968) called "the Tragedy of the Commons". However, events such as the collapse of the Atlantic fisheries in Canada and the impending collapse of the Pacific Salmon fisheries are signalling a need for change. The public is demanding significantly greater local participation in resource decision-making. This has led to serious criticisms of the philosophical, theoretical and empirical bases of conventional, centralized western approaches to common property resource management.

The purpose of this section is to expand on this discussion of common property resource theory. It provides the background for a discussion of the role of codes of conduct in facilitating a more self-regulatory approach to stewarding common property resources such as orca habitat.

\subsubsection{Resource management and the tragedy of the commons}

Conventional economic theory refers to common property as "a category of things which no one can make a property claim and to which no one can be excluded from access or use" (Griggs, 1991:12). In following this line of 
thought, the contemporary Western understanding of common property has held that natural resources are open-access free goods, "owned by everyone and therefore no one" (Berkes and Farvar, 1989:7). This interpretation of the term, together with the belief that all people are essentially driven to act in individual self-interest, has laid the foundation for current approaches to the management of common property resources such as fish, water, air and wildlife.

In 1968, Hardin vividly captured the prevalent belief that all common property resources were doomed to overexploitation and degradation by users acting in rational self-interest, even at the expense of the common good.

Hardin's thesis was summarized well by Berkes and Feeny (1991: 48):

Imagine a village commons, said Hardin, in which a number of herders graze their cattle. What is to stop the herders from adding more animals to their herds? Each herder would find it very attractive to augment his or her herd, even if this meant that the carrying capacity of the grazing area would eventually be exceeded. For each herder as an economically rational decision maker, it would be profitable to graze more animals because the herder would take all the profits from the extra animals but would bear only a fraction of the cost of overgrazing. Thus, individual rationality would lead to a collective tragedy (in the sense of ancient Greek tragedies) from which there was no escape, declared Hardin.

The only way to avoid the tragedy of resource over-exploitation, Hardin argued, was through either privatization or state control (Hardin, 1968). 
Hardin's "tragedy model" and its proposed remedies of privatization or state ownership outlined the framework of understanding of resource managers and environmentalists for decades afterwards. Berkes and Feeney (1990:48) explain how the model has come to be accepted as a paradigm,

Few questioned Hardin's assumption of individual interest unchecked by social relations, and his emphasis on competition (rather than cooperation) as the overriding relationship that shaped interactions among resource users. The tragedy of the commons became an important part of environmental education and applied resource management curricula, and provided the essential insight for the genesis of environmental problems for generations of students.

Legislated systems or the privatization of commonly-held resources are still widely thought to be the only policy solutions to what would otherwise lead to the inevitable tragedy of over-exploitation (Ostrom, 1990:7).

Simple models, like Hardin's, though clear and powerful, are often not transferable to complex, real-life scenarios. Hardin's thesis does not withstand empirical observation. Many of its implicit and explicit assumptions have been challenged extensively in recent years (Griggs, 1991:17).

Accountability mechanisms needed in all systems do not come exclusively from government. Conventional resource management operates on the fundamental model of the tragedy of the commons. The "tragedy" is that the individual does not have the mechanism for making others think long-term, 
so they give up and decide to get as much as they can. They feel that since somebody else will over-exploit the resource anyway, self-restraint will be of no benefit to them (Pinkerton and Weinstein, 1995).

In the tragedy of the commons model, individuals seem to be condemned to act in their own short-term, self-interest, even to the detriment of the resource in the long-run. What seems to be rational in the short-term is both individually and collectively irrational in the long-term. This would describe a whale watching vessel that approaches pods of orcas at irresponsible speeds and makes every effort to stay on top of the whales. This could be a very short-term thrill for the clients on that vessel, but could cause severe longterm consequences by driving the whales away from the area.

The tragedy of the commons model does not demonstrate how people behave when communities exert stewardship rights. Communities can make rules which they can and do get their members to obey. The nature-based tour operators of Gwaii Haanas B.C. have written their own code of conduct which they both value and adhere to for the long -term sustainability of the environment and their businesses (per com Falconer, 1996).

The common property resource management paradigm traps managers into thinking that the only possible arrangements are the ones we already have. The current arrangements tend to make at least some people behave in the 
way that the tragic models predict. But the models, and the resource users are bound by the situation, not by what is possible. It is possible to modify key aspects of our management institutions to allow for more personal accountability and collective responsibility for the long-term viability of the resources at issue. The policy alternatives and recommendations sections that follow in this paper discuss some of these alternatives.

\subsection{CURRENT LEGISLATION REGARDING MARINE ENVIRONMENTAL MANAGEMENT}

Marine habitats are almost always associated with open ecosystems that are large and dynamic. Several pelagic, anadromous fish species, and many marine mammals, as well as invertebrate species, undertake far-ranging migrations within such habitats for feeding and reproduction purposes (Canadian Heritage, 1994). Sea water can carry large numbers of atmospheric and land-based pollutants long distances and to great depths. This makes marine areas vulnerable to pollution generated at very distant sites. As a consequence, stewardship of marine habitat must then take into account the reality that marine resources do not stay within boundaries imposed for administrative purposes (Dearden and Duffus, 1993; Beckmann, 1994).

The scientific understanding of marine ecosystems is not well developed. As a result the impact on human activities cannot be predicted accurately. Marine systems are not uniform, and some specific areas are more highly 
productive than others (Beckmann, 1994). These highly productive areas, as well as other marine environments that contain key areas critical to the survival of the larger ecosystem, require creative approaches to environmental stewardship.

\subsubsection{Legislated systems in marine environments}

A significant problem with protecting and managing marine areas in Canada is the complexity of legislation and jurisdictions affecting the marine environment. There are at least 36 federal acts and 20 provincial and territorial acts that relate to the protection and use of the marine environment and marine resources (Beckmann, 1994). These acts and sets of legislation confer responsibilities on a large number of federal departments and agencies: DFO, Department of Transportation, Canadian Heritage and provincially BCMOELP. No workable mechanism currently exists to direct policy-making and coordinate the various roles (Beckmann, 1994). Mandates overlap or are too vague to give any single department clear command to coordinate federal policies and programs for marine environments (VanderZwaag and Lamson, 1986). 
The agency primarily responsible for management of orcas in Canadian waters is DFO. The Department has management responsibility for orcas under the jurisdiction of the Fisheries Act. It is mandated to protect habitat and provide for enforcement and research. The Cetaceans Protection Regulation of the Fisheries Act provides jurisdiction to prevent chasing, shooting at or harassing of whales. A legal description of harassment has yet to be formulated (per com Ellis, 1996). Until a legal description of harassment has been defined, the main instruments of the Department of Fisheries and Oceans for deterring harassment are whale watching guidelines and education (JSKWC, 1991). These educational initiatives are discussed later in this chapter.

British Columbia Ministry of Environment Lands \& Parks

The British Columbia Ministry of Environment Lands \& Parks (BCMOELP) is responsible for the protection of orca habitat under the Ecological Reserves Act. Order-in-Council 1134, technically limits provincial jurisdiction to the land covered by water and to the upland portion of any ecological reserve (JSKWC, 1991). 
The Ecological Reserves Act is provincial legislation which has no authority in marine waters. Consequently, provincial jurisdiction is limited to protecting the land portion of orca habitat in ecological reserves. This leaves DFO with the jurisdiction for protecting orca habitat. Currently, there is no agreement for enforcement of Federal legislation, such as the Fisheries Act by provincial representatives within marine ecological reserves (JSKWC, 1991).

The B.C. MOELP's management strategies for minimizing disturbance of orcas has focused on education (JSKWC, 1991). Most disturbance results from lack of awareness rather than poor intentions (per com Taylor, 1994). Once informed, most people are generally very willing to comply with whale watching guidelines (per com Taylor, 1994).

\subsubsection{International legislated cases}

International examples of regulatory or legislated approaches are examined in this section. The discussion provides a backdrop for comparing and contrasting the management style of regulatory and voluntary approaches to management. An examination of some regulatory features are given to illustrate legislated involuntary regulations.

The regulations applied to viewing humpback whales in Glacier Bay, Alaska are strictly enforced through a licensing system. Strong presence of officers 
from the National Marine Fisheries Services exists to ensure compliance (United States National Park Service, 1990). The popularity of Glacier Bay to large, passenger cruise ships has made licensing a practical solution to managing vessel traffic in the confined space used to view humpbacks. The licensing system which restricts the number of vessels in the Bay at any one time works well in this situation. It assists cruise ships to plan their schedules (National Marine Fisheries Services, 1987). These restrictions help to ensure a quality experience for clients along with fewer vessels in the Bay and less disturbance of the humpbacks. Enforcement of the restrictions is relatively easy as it is a small and confined area (National Marine Fisheries Services, 1987).

Large numbers of vessels viewing humpbacks in Hawaiian National Marine Parks have made necessary a strong presence of National Park Services officers. They attempt to keep the disturbance of the Humpbacks to a minimum (National Marine Fisheries Services, 1987). The number of boats watching whales is not controlled through a permit system in this situation. Instead, boats are required to maintain a 300 meter buffer around whales. The National Marine Fisheries Service chose to regulate allowable distances to whales rather than regulating the number of vessels because the area is not geographically well-defined, and also receives high levels of non-whaleoriented vessel traffic. 
In Hervey Bay Marine Park, Australia, a designated area of the Bay has been declared a "Whale Management \& Monitoring Area". This allows management of human activity in the vicinity of humpback whales (Franklin, 1995). Through legislative regulations a permit system has been put in place. It limits the number of vessels in the bay to ensure the protection of the whales. Regulations under this permit also govern approach distances and methods of approach to whales. Although the legislated system of permits was in place, the commercial whale watching operators found it necessary to develop and adopt a code of conduct to help ensure a rewarding experience for visitors. The code of conduct has proven to be extremely beneficial in regulating the behavior of permitted operators around whales (Franklin, 1995).

Management of marine mammal watching in New Zealand, through the development of the Marine Mammal Protection Regulations 1992, provided two principal mechanisms for managing commercial whale watching activity. These were a permit system, and a set of operating regulations (Baxter and Donaghue, 1995). This system of management highlighted the need for public education of uncontrolled recreational viewing. Recreational whale watchers are often unaware of appropriate behavior around whales. Codes of conduct as an instrument for public education was seen as the only practical compliance option to adopt with respect to recreational viewing of 
marine mammals (Culver and Burke 1986; Baxter and Donaghue 1995; Herzing 1995).

Donaldson (1982:165) supports the use of codes as an instrument in managing human behavior :

...codes work in areas of behavior where it is very difficult to develop an involuntary method of regulating behavior and/or where it is difficult to monitor...the opprobrium of colleagues (watchdog effect) can effect more reliable compliance because of a personal approach rather than the impersonal eye of a government bureaucracy - the industry may be in a better position to exercise a watchful eye than the government.

Large ocean ecosystems are very difficult to actively police due to their physical expansiveness. They lend themselves naturally towards using a code of conduct as a voluntary regulatory measure. Legal agencies often have little desire to get involved in protecting large marine areas through legislation and policing for practical and financial reasons (per com Lubar, 1993).

\subsubsection{Pitfalls Of Legislated Approaches}

BCMOELP is responsible for the protection of orca habitat under the Ecological Reserves Act. Provincial jurisdiction is limited to the land covered by water (the ocean bottom within the reserve). This has left BCMOELP attempting to protect orcas with no authority in the marine waters that the whales inhabit. No agreement exists for enforcement through federal legislation (e.g. the Fisheries Act), which could protect the whales through 
provincial management within marine ecological reserves (JSKWC, 1991; per com Lochbaum, 1993).

Although DFO is responsible for the management and protection of killer whales, their main management priority continues to be fish (per com Lubar, 1994). As Beckmann (1994:37) states, "...the DFO continues to focus on the management of fish to the exclusion of its broader mandate to manage oceans", including areas aimed at protecting killer whale habitat.

\subsubsection{Orca Culture}

The following discussion highlights some of the key characteristics of orca behavior which are important to consider in addressing the management issues associated with whale watching. A brief summary highlighting the natural characteristics of orcas along the B.C. coastline is given in this section. Orca culture, is potentially threatened by increasing vessel traffic in Johnstone Strait (Bigg 1983; Blood, MacAskie and Low, 1988; Briggs, 1991; Ford, Ellis and Balcomb, 1994).

Three races of the species Orcinus orca have been identified along the B.C. coastline: resident, transient and off-shore (Ford, Ellis and Balcomb, 1994). Although their ranges overlap, they display behavioral differences and do not seem to mix. Resident whales feed exclusively on fish, whereas transients 
feed upon marine mammals, swimming ungulates and the occasional sea bird. Residents predictably visit the inshore areas during summer, while transients can be observed irregularly along the entire coast at any time of the year. Residents travel in pods of 10-20 members while transients rarely travel in groups of more than five whales. Residents use 'core areas' seasonally in Haro Strait off southem Vancouver Island and in Johnstone Strait. Off-shore orcas are usually found in large groups of 30-60 whales. They are rarely seen in protected coastal waters. Whale researchers believe that offshore whales spend most of their time on the edge of the continental shelf, feeding on schooling fish and perhaps marine mammals (per com Ford, 1995). All orcas communicate with a dialect of discreet calls that is unique to their pod. Resident pods are matrilineal, with members staying together for life. It is the resident pods, living in close family units, in core habitats such as Johnstone Strait that face the greatest potential danger to their well being with increased human activities in their core habitat areas.

Over $90 \%$ of the orcas that use Johnstone Strait each summer also frequent Robson Bight (Michael Bigg) Ecological Reserve (RBMBER) to socialize, rest and rub on underwater pebble beaches. Rubbing behaviors have rarely been seen in other areas of the world. Nowhere have these behaviors been observed with such frequency or occurring with such large numbers of whales as in Robson Bight (Briggs, 1991). In his recent studies Briggs has shown that killer whales in Johnstone Strait spend as much as $20 \%$ of their 
time in RBMBER, with that time divided almost equally between the Bight, the rubbing beaches, and the remainder of the Reserve.

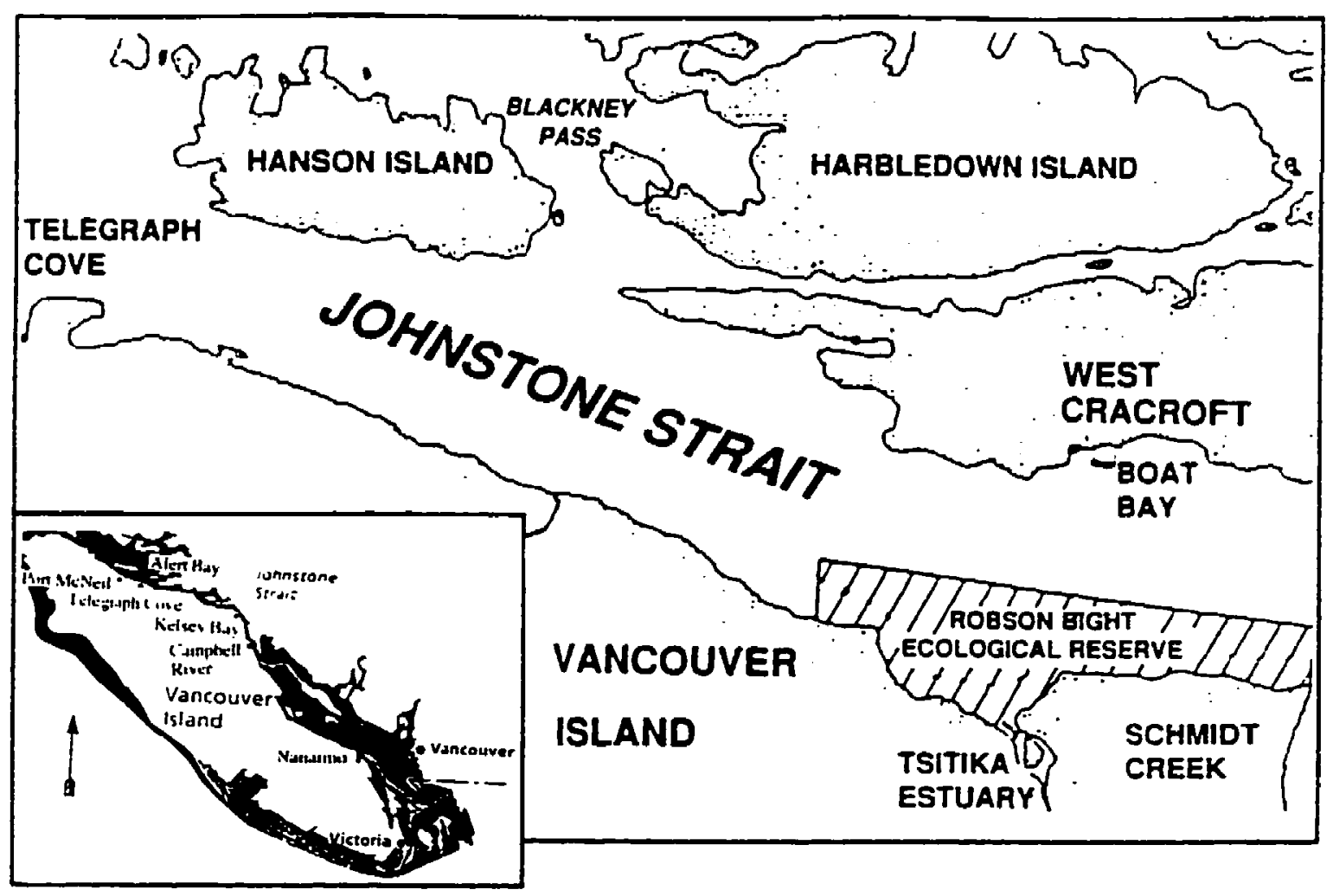

Figure 2.1 Johnstone Strait and Robson Bight (Michael Bigg) Ecological Reserve

The rubbing behavior has only been observed in association with resident whales. Rubbing whales swim slowly back and forth over pebbly barnaclefree beaches, with their flanks, bellies or sides gently touching the pebbles. When rubbing, Briggs (1991) found the whales to be highly sensitive to human activity. Vessels and the presence of humans onshore within 300 meters of the rubbing whales causes avoidance behaviors. Human use of the 
area is causing short-term disturbance of these orcas. In the longer term, it might cause these whales to leave this habitat.

Resident orcas seem to have a strong dependence on the availability of such habitat. They have a highly organized and developed culture. It is therefore easy to argue that orca communities have an intrinsic right to exist, and that special measures should be taken to ensure the health and long-term sustainability of their habitat (Reece, 1996). Further research is necessary to accurately predict the long-term consequences of human activity in the orcas critical habitat (Briggs, 1996).

\subsection{THE ROLE OF VOLUNTARY COMPLIANCE SYSTEMS}

Given the complexity of legislation and jurisdictions affecting marine environments in Canada, the lack of provincial jurisdiction, and the low priority status given to orcas by the DFO, it seems clear that new approaches to the management of such critical common property resources are required.

Codes of conduct are presented in the following section as an alternative stewardship model that involves direct democracy, self/group reflection, decentralization, and empowerment in order to achieve results that are ecologically sustainable and socially just (Aberley, 1996). 
Centralized regimes tend to be cumbersome and ineffective in addressing these issues. Governments do not have the resources to effectively manage the use of these marine resources over large areas. Moreover, once local users are deprived of responsibility for the resources on which they depend, opportunistic behaviors may become the norm, and unsustainable scenarios are likely to develop (Ostrum, 1990). On the other hand, community-based systems, offer an opportunity to use localized social censure as a powerful deterrent to opportunistic behavior (Ostrum, 1991). As Grima and Berkes (1989:49) point out: "The community has a built-in incentive to stay well within the biological limits of the resource which have been learnt by experience. The community also has at its disposal the requisite social coercive mechanisms to force compliance with expected harvests."

One of the potentially valuable management tools in this regard is codes of conduct. These codes can act as a self-regulating "market control" system for encouraging sound stewardship. The following section describes some of the key characteristics of codes of conduct.

\subsection{CODES OF CONDUCT}

The Oxford English Dictionary (1988:152) defines "code" as "a systematic collection or digest of the laws of a country, or those laws relating to a 
particular subject." The Oxford dictionary (1988:166) defines "conduct" as "to manage or direct" and "ethics" as "a set of moral principles to be observed by a profession".

Ethics researchers suggest that codes of ethics are useful for large, well organized, established, institutional groups such as the medical profession. (Winkler, 1993:418) Codes of ethics serve to help guide people in such organizations when making a wide range of moral decisions. Conversely codes of conduct seem to be more applicable for small, less established associations, that could utilize a more specific set of guidelines in their day-today operations. Codes of conduct in the context of this study are defined as a systematic collection of the laws of a particular subject (Winkler, 1993).

A code of conduct can potentially regulate the behaviors of tourism operators. By developing and implementing such codes, the experience of the visitors, the conservation of critical natural habitat, and the ultimate long term sustainability of many tourism operations may be enhanced.

\subsubsection{Benefits of a self-regulation}

A code of conduct demonstrates common understanding among operators about the self-imposed guidelines which they have developed (Anderson, 1986). This common understanding may encourage a culture for 
communication. Codes provide opportunities to avoid conflicts, and to resolve them if and when they occur (Arrow, 1979).

While providing common understanding, codes of conduct may also put the individuals of a community in the same moral ballpark and elevate the moral conscience of the group (Friedmann, 1991). When considering issues of habitat preservation, for example, a common base understanding can be reached with respect to tolerable, and/or intolerable forms of behavior within natural habitats. Common moral understanding is crucial where people must share common property resources. It can help competing individuals to better understand each other's needs. For instance, by using codes of conduct as a management tool, users of the resources might come to an agreement on the best use of them in a natural area. Potentially, the competition that presently exists for many scarce resources could be eliminated (Pinkerton and Weinstein, 1995). Increased common understanding could allow for the development of consensus-based best environmental practices in a sensitive ecosystem (Williams and Hawkes, 1993).

Without this opportunity for discussion, individuals may continue to behave in the way they believe, regardless of the potential negative impacts their actions may have on the environment. As a consequence, codes of conduct may act as catalysts for the creation of innovative management techniques, 
for the benefit of an area's ecology and for the community that depends on the natural resource base.

\subsubsection{Community-based stewardship}

Stewardship of natural resources is not simply a matter of licensing the users and defining protected areas such as ecological reserves or special management zones. Stewardship guided through a code of conduct can be far more inclusive. However, to be effective, the people involved in developing the codes must then accept responsibility for their actions. In the process of code development, codes become more than documents. They represent a way of bringing knowledge and practice to bear directly on future actions. Face-to-face interaction is central to codes of conduct development (Kaza, 1988; Friedmann, 1993).

Existing literature and research concerning the development of codes of conduct suggest that codes should be written simply and involve industry in the process. Arrow (1979: 227) writes,

An ethical code is useful only if it is widely accepted. How do such codes develop? They may develop as a consensus out of lengthy public discussion of obligations, discussion which will take place in lecture halls, business journals, and other public forums. ...the codes are communicated by the very process of coming to agreement. 
The interest that is generated through discussion between a variety of stakeholders can spread enthusiasm and encourage the code's ultimate success, once established.

\subsubsection{Human Capital}

Debates in resource management regarding sustainability currently focus around the extent to which natural capital (air, water, soil, flora, fauna, ecological systems) can be safely converted to manufactured capital (machines, buildings, infrastructure) (Daly, 1994; Pinkerton and Weinstein, 1995; Wackernagel and Reece, 1995). Commurity-based stewardship of natural resources takes this into account, but also recognizes the importance of "human capital." Human capital is the stored wisdom of individuals and communities that has been built up over time. It is the way of knowledge, skills, experience, attitudes and values about how to solve problems (Pinkerton and Weinstein, 1995). The importance of human capital becomes evident, for example, when a group of long-time local residents notice the absence of whales in places where they appeared for generations. The locals may also relate the timing of the disappearance of the whales to other occurrences of the past such as weather patterns or the instability of salmon stocks. Their knowledge, combined with other research observations, can result in new alternatives to managing the resource. 
Human capital also encompasses peoples' willingness and ability to make (or support) rules that govern their own behavior. When a problem or issue arises regarding a resource, the resource users understand how their communities and organizations are likely to respond. They know how important the problem is, how much they value the resource and how many meetings they are willing to attend to discuss the issue. They also know what they believe is a fair and workable solution, one they would be willing to support (Pinkerton and Weinstein, 1995).

Community involvement in the planning process allows for more detailed and specific knowledge to be brought to the process than if only expert knowledge was used. Involving the community may also strengthen communal responses, and channel them away from blind resistance to paths of compliance (Friedmann, 1993). Involving the community seeks to tap into people's capacity for proactive practice and may create a sense of collective solidarity.

A community of whale watching operators have stored wisdom, built up over years of traveling on the water and observing natural phenomena, such as the behavior of orcas. The human capital that they have cumulatively acquired over time puts them in a position to develop a code of conduct to guide their operations. A whale watching community can then be proactively involved in the management process through their code. In this 
way, local knowledge can be transformed into a written document, and the natural resources (i.e. orcas) receive "grass roots" management from a community. Guided by a code of conduct, the community with a large presence in a given area may then be an effective steward of the natural resources.

Government regulators, and consequently the resource, can pay dearly when they ignore the value of this aspect of human capital. By involving the community in designing strategies such as community-based codes of conduct to solve problems, many pitfalls can be avoided. A discussion of codes of conduct is given in the following section. 


\subsubsection{Critical code content}

Two existing codes of conduct are examined here as background to the development of a code of conduct. The codes of conduct chosen for review are those of the Gwaii Haanas B.C. commercial tour operators, and the river rafting outfitters on the Tatshenshini river. A key focus of both codes is operator behavior. The typical thematic thrusts of these codes emphasize the importance of communication between operators. These codes also include specific guidelines for responsible behavior around wildlife.

The guidelines expressed in these two codes are designed to pay close attention to human behavior around wildlife, and to ensure a quality experience of peace, quiet and solitude with nature for the clients. The elements of the code are very specific in their expectations of the tourism operator. Through focusing attention on the daily operations, these codes provide voluntary tool for encouraging the long-term sustainability of the industry's resource base.

The literature revealed many examples of tourism operations using codes of conduct in local, national and international settings (ARA Consulting Group, 1991; Baxter et al. 1995; de Calventi, 1995). Before evaluating the utility of a code of conduct in encouraging compliance to behavioral norms, it was important to determine whether codes of conduct were already in use in 
marine tourism settings. The literature identified common elements of codes of conduct. Codes of conduct are in use as a public education tool in areas where it is difficult to monitor vessel behavior (JSKWC, 1991). Voluntary codes of conduct are effective in providing the watchdog effect of colleagues as a personal approach to enforcement rather than 'command and control' regimes (Arrow, 1979), and are an effective tool in giving stewardship rights to a community (Pinkerton and Weinstein, 1994). To ensure compliance to codes of conduct a number of inherent social coercive mechanisms exist (Grima and Berkes, 1989; Ostrum, 1991). The literature review also found that codes demonstrate common understanding among operators (Friedmann, 1991), act as a catalyst for education (ARA Consulting Group, 1991), and therefore help to eliminate competition for scarce natural resources (Pinkerton and Weinstein, 1994).

The literature review also revealed a gaping hole in alternative policy research; rarely were codes of conduct assessed on their ability to encourage compliance to established guidelines. This suggested a need for a survey to determine the utility of codes of conduct in encouraging compliance to accepted whale watching norms. Furthermore, since codes of conduct are only useful if tour operators are motivated to improve environmental performance, there was also a need to identify tour operators' motivations for code compliance. 


\subsection{Compliance to Societal Norms}

People act in a way that reflects their moral beliefs. Codes of conduct only suggest how they will behave, not whether they will behave (Winkler, 1993). Commercial whale watching operators, as a community using "common" natural resources as their product, have developed a set of social norms. These social norms have become internalized through a social learning process from years on the water around whales. These norms then become moral standards against which the operators weigh their own actions. This section will discuss the theory of social norms. The discussion relates to commercial whale watching operators' compliance to a set of agreed upon norms in a written code of conduct.

\subsubsection{Prosocial behavior and natural resource protection}

Prosocial behavior theory attempts to explain why people do or do not help others who are in need (Gramann and Vander Stoep, 1986). Research in this area has traditionally dealt exclusively on discovering techniques that promote prosocial behavior between humans towards one another. Gramann and Vander Stoep (1986) extended the scope to encompass humanresource relationships, arguing that resource protection is prosocial behavior, and that existing theories can explain human-resource relationships. The relationship of whale watching operators behavior around whales and other 
natural and cultural resources will be explored through a discussion of social norms.

\subsubsection{The role of social norms}

Norms are the widely shared beliefs of societal expectations and tolerances (Schwartz and Howard, 1981). Norms can carry the weight of official sanctions or they may be informal, relying on external disapproval as a sanctioning force. For instance, in Gwaii Haanas, an operator known to not comply with the established social norms of the area may be cut off from the important whale sighting network (per com Burke, 1996). This network is crucial to the success of operators finding whales in large marine areas. This mechanism of external disapproval can work very effectively as a sanctioning force. Individuals internalize norms through social learning, and these norms then become moral standards against which they weigh their own actions (Schwartz and Howard, 1981).

The literature on prosocial behavior theory identifies three main reasons why people behave prosocially (Schwartz, 1977). The first reason is moral obligation, which attempts to explain why most people want to do the right thing. Moral obligation can be strengthened when people are made aware of the negative consequences of certain actions and take responsibility for avoiding those behaviors (Schwartz and Howard, 1981). Through the process 
of developing a code of conduct, whale watching operators are made aware of the expected behavioral practices, as well as the consequences of noncompliance. Noncompliant behavior may be sanctioned with suspension from a tour operator association, or publicizing the names of noncompliers. However, people are not always guided by their feelings of moral obligation. This seems to be true, especially when a person feels that the social or psychological costs of complying are too high. In such cases there may be a tendency to rationalize the denial of responsibility (Schwartz and Howard, 1981).

A second reason people behave prosocially is because of a strong desire to please others, and in turn create a sense of belonging to important reference groups (Carnevale et al. 1982). The community of whale watching operators in a given area are very dependent on each other for safety, whale sightings, and business referrals. Behaving prosocially and becoming an accepted member is therefore in the best interest of all operators.

Finally, people may conform to norms when threatened with some kind of punishment for non conforming behavior (Gramman and Vander Stoep, 1987). A whale watching operator found to be harassing whales or fouling limited campsites may be ostracized from the community. The weight of this external sanction will weigh heavy on this operator's business survival (per com Borrowman, 1996). The whale watching community is close knit and 
each operator depends on the others for safety, finding the whales and professional reputation. The next section will attempt to explain why such prosocial behavior may occur, given the potential repercussions of external sanctions.

\subsubsection{Reasons for normative violations}

Six types of normative violations that may result in damage to natural resources have been identified in the social psychology literature (Gramman et al. 1986). One of the reasons a person may violate norms is because the individual is unaware of the expected behavior in an area. Campers are often unaware of effective techniques of human waste disposal in critical camping areas. This can result in the area becoming degraded and unusable for camping. Unaware of the expected no-trace camping techniques, these campers commit normative violations without a real intent to damage the natural area. Ignorant of the natural patterns and behavior of wildlife, visitors to natural areas often approach sighted wildlife with little care or sensitivity. These actions may be completely innocent due to a lack of understanding of expected behavior around wildlife.

A second type of violation results from environmental cues in the form of others' behavior or traces of that behavior. For instance, in Haro Strait off of Victoria, B.C., up to 200 whale watching boats can be following one pod of 
whales at the same time. All it takes is for one of these boats to move irresponsibly close to the whales for many of the other boats to follow in close as well (per com Gjerdalen, 1997). Another example of this violation can occur in native cultural sites where individuals may observe, or see traces of digging beads out of a native midden. The individuals may assume that this is appropriate behavior and act on this cue to violate the integrity of the midden.

A third type of violation occurs when people know of a rule, but are unaware of the negative consequences that ignoring it may have on the environment. For example, most campers are aware of the norms around keeping campsites clean of food and storing food safely and well away from sleeping areas. When such norms are not followed, wildlife such as bears and raccoons, can be attracted to campsites putting the animals and the campers in danger. Whale watching boats may be well aware of the norm of not following a pod of orcas closer than 100 meters but may still choose to ignore the norm. Operators of such boats may be unaware of the negative consequences of this behavior in terms of the whale's ability to rest, communicate and hunt (per com Briggs, 1996).

A fourth category of violation that may occur results when the norm is judged to be unreasonable or unrealistic for the person to abide by. In this case, the denial of responsibility is justified through rationalizing that the 
change in behavior would be impossible without disrupting their goals or objectives. The operator of a whale watching boat may feel that very close encounters with whales are important to the satisfaction of the visitors onboard. This operator, most likely, is well aware of the established norms of boat behavior around whales, but chooses to ignore them, justifying the behavior through the goal of customer thrill and satisfaction.

The powerful social influence from important reference groups results in the fifth identified normative violation. In this case, an individual's conformity to a violation reinforces their membership status by providing observable evidence of their commitment to group norms (Gramman and Vander Stoep, 1987).

The sixth and final violation consists of willful acts of vandalism. Motivation for these actions may result from a desire for financial gain, ideological protest, revenge, malice or fun (Zimbardo, 1976). One case of such willful vandalism on orcas was witnessed in Johnstone Strait. A high powered and highly maneuverable Zodiac harassed a pod of orcas by steering into their path and motoring through them with no regard for the welfare of the whales or the safety of the visitors aboard the boat (per com Borrowman, 1993). 
Given that normative violations do occur for a number of reasons, a discussion follows outlining the applicability of deterrence models to the whale watching community.

\subsubsection{Deterrence models}

While deterrence models have been traditionally restricted to legal sanctions, internalized norms and attachment to significant others may also be seen as potential sources of punishment (Grasmick and Bursik, 1990). Like government-imposed legal sanctions, internalized norms vary in both their certainty and their severity (Meier et al. 1984). The internalization of a norm poses the threat of guilt feelings or shame for doing something which the person considers morally wrong (Williams and Hawkins, 1986). Shame can be considered as a form of potential self-imposed, or reflective punishment that can be viewed as more or less certain and more or less severe.

Significant others such as friends, family and peers, whose opinions about a person are considered important by that person, are another potential source of punishment threat (Hirschi, 1969). This form of punishment occurs when people observe a violations of a norm by a person and that person feels embarrassed. The socially imposed punishment of embarrassment may carry long-term consequences, such as a loss of valued relationships and restrictions on opportunities to achieve goals over which significant others 
have some control (Grasmick and Bursik, 1990). As in the cases of legal sanctions and shame, embarrassment also has the dimensions of certainty and severity.

Evidence presented in the sociology literature (see Williams and Hawkins, 1989; Grasmick and Bursik, 1990) point to shame, not embarrassment, as the threat which has the greatest direct effect on normative behavior. While shame is a self-imposed punishment, embarrassment is a socially imposed punishment. This highlights the importance of internalizing norms as a selfimposed punishment threat which can lower the expected violation of a norm (Grasmick and Bursik, 1990). The importance of internalizing norms (self-imposed) may be explained in this way. When confronting a specific violation of a norm, individuals might know with certainty whether they would feel ashamed, since they themselves are the punishing agent. In contrast, individuals can only estimate the probability of legal sanctions or embarrassment, as they do not know for sure how the authorities or significant others would react. A whale watching situation will illustrate the applied significance of this theory to this research. The shame that an operator may impose on themselves for a normative violation such as following a pod of orcas too closely (subsequently a group of recreational whale watchers follows them in) has a more direct effect than the potential embarrassment that could occur if the operator's peers had observed the behavior and called him for it. 


\subsubsection{Perceived certainty of social condemnation as punishment}

The perceived certainty of punishment for normative violations has a deterrent effect, while the perceived severity of punishment does not (Paternoster, Saltzman, Waldo and Chricos, 1983). Research on perceived risk suggests that the perception of formal legal sanctions plays only a small role (if any) in the production of conformity (Saltzman, 1982). Individuals who appear to subscribe the most to social condemnation of normative violations are the ones who tend to view punishment as the most certain. They may commit fewer violations because of social condemnation, rather than fear of punishment (Gibbs, 1975).

One of the better validated theories of crime and delinquency is Hirschi's (1969) social bonding theory. Hirschi claims that individuals who are attached and involved with others through strong social bonds are less free to break rules because of a common commitment than those whose ties are weak. An individual may become committed to conformity because prospects for the future might be threatened should one's deviance be noticed. Hirschi (1969: 266) summarizes this: "... one is committed to conformity not only by what one has but also by what one hopes to obtain. Thus 'ambitions' and/or 'aspirations' play an important role in producing conformity." 
Hirschi's social bonding theory clearly supports the strong role that codes of conduct can play in building community bonds between whale watching operators. As the operators work together in developing guidelines for their industry through a code of conduct, they build social bonds and commit to compliance to the normative behavior that they are helping to write down. Individual ambition for the success of their business also may make them more dependent on good relations with the other operators. Acceptance and support in the community is critical to the long-term success of their whale watching business.

The research literature on social control processes argues that the inhibition of, or a propensity toward, behavior that deviates from the norm may best be explained by extra-legal influences such as moral beliefs, informal social sanctions, and some kinds of conventional commitments (Hirschi, 1969). It is these extra-legal or self-imposed sanctions that make codes of conduct an effective compliance tool in the stewardship of natural resources. 


\section{CHAPTER THREE: METHODS}

\subsection{Introduction}

This chapter describes the methods used to conduct the research in this study. It is divided into three sections. Research questions for the study are described in the first section. The second part describes the use of a case study for research and the geographical focus of the investigation. The third section describes the survey objectives, design, sample selection and analysis.

\subsection{Research Questions}

The overall purpose of this research is to evaluate the utility of codes of conduct to commercial whale watching operations. More specific questions relating to this goal are:

(1) How has the code been useful to operators?

(2) How does a code of conduct encourage compliance to agreed upon guidelines?

(3) What are the most effective methods of encouraging compliance? 


\subsection{The Case Study}

This research involved the use of a case study approach to address the three questions stated in the previous section. Case studies are utilized by researchers to explore a single entity or phenomena ("the case") bounded by time and activity (process, social group). They collect detailed information by using a variety of data collection procedures during a sustained period of time (Creswell, 1994). The use of a case study is an appropriate investigation technique when the research concerns the "why" questions, and when control over behavior is not required, and the research focuses on contemporary events (Yin, 1989). The research conducted in Johnstone Strait met these requirements. It was concerned with why a code of conduct might be an appropriate voluntary policy alternative to "command control" systems, and why people do comply, or do not comply, with the guidelines outlined in the code. The research dealt with a contemporary event, the dayto-day operations of commercial whale watching operations.

In Yin's (1989) terminology, the research design was single case/holistic. As such, it should only be considered exploratory, since the researcher was not aware of any other use of case studies in evaluating the utility of codes of conduct in encouraging compliance to agreed upon guidelines. Extension of 
the case study to other whale watching areas would greatly strengthen the ability to generalize results from this research.

Johnstone Strait was selected for this case study for two specific reasons. The area has incredible potential as a world-class whale watching destination, and the tour operators' showed genuine interest in developing and implementing a code of conduct that would help to guide their day-to-day operations. As such, the area offered an opportunity to work with a concerned community to evaluate the code's usefulness in encouraging compliance to whale watching guidelines.

The research only concentrates on the evaluation of the utility of the Johnstone Strait code of conduct in encouraging compliance to agreed upon whale watching guidelines. This evaluation strives to determine the most effective methods of encouraging compliance to the guidelines.

\subsubsection{Description of the case study area}

Johnstone Strait (Figure 2.1) is known to be the best location in the world to observe and research orcas in the wild (Ford, Ellis and Balcomb, 1995). Up to 190 resident orcas use Johnstone Strait each summer, primarily to feast on the migrating salmon. Johnstone Strait is used more frequently by orcas than any other coastal waterway in British Columbia (Blood and MacAskie, 1988). Johnstone Strait is unique among the coastal areas of British Columbia 
because orcas use the area so predictably (Hoyt 1990; Briggs 1991; Ford, Ellis and Balcomb, 1995). Orcas are seen or heard throughout the year in Johnstone Strait, although sitings become much more frequent from June to September.

Johnstone Strait is a deep channel, $40 \mathrm{~km}$ long by $4 \mathrm{~km}$ wide. The Strait separates northem Vancouver Island from mainland British Columbia and from hundreds of nearby islands. It is part of the protected Inside Passage of the Northwest Coast, providing a relatively safe route to tugs, fishing boats and Alaska-bound cruise ships. The shore on both sides of the Strait is high and rugged, with mountain ranges rising almost abruptly from the sea to snow capped peaks, 1,600 meters high. The land is densely forested with some of the largest, densest stands of timber on the continent. Over the last fifty years logging has changed this landscape so that the bald patches of the clear cuts on the mountains are a constant reminder of the increasing pressures of humans on the ecology of this area.

The following description of Robson Bight Michael Bigg Ecological Reserve (RBMBER), within Johnstone Strait, is included as it is critical orca habitat where orcas are very sensitive to human activity. A prominent focus of the code guidelines is to keep whale watching activities out of RBMBER. The reserve is located in western Johnstone Strait along the Vancouver Island shore (Figure 3.1). The Reserve contains marine and terrestrial components 
and is 1753 hectares in area. It is centered around the Tsitika River estuary. The marine component of the reserve covers 1248 ha. with an outer boundary extending $1.0-2.3 \mathrm{~km}$ from shore. The terrestrial component is 505 hectares. It forms a 200-1500 m wide buffer along the shoreline (Blood et al. 1988).

RBMBER was established in 1982 for the following reasons: to protect key habitat for whales; to prevent whale harassment while using these habitats; to maintain unique opportunities to research and observe whales; and to protect a pristine estuary, shoreline and vegetated slopes (JSKWC, 1990). The Johnstone Strait code of conduct endeavors to support the conservation goals of RBMBER. It highlights the reserve on a map and printing the prohibitions of human use for the reserve (Appendix 1).

\subsubsection{Data Collection}

Observations for the case study occurred during August 1990 and September 1993. Other data sources for the case study were derived from survey instruments, interviews with the whale watching tour operators and resource guides, personal observation and documentation from 1993 through 1996. 
The primary method of data collection involved the use of a survey instrument. Face to face interviews with key informants constituted the second method of data collection. Personal observation of the environmental practices, policies and procedures of the whale watching operations in Johnstone Strait was the third method employed to gather information for the case study. Personal observation included many days of viewing the whale-watching practices of the operations of two large motor-powered vessels, one large sail-powered ship and a rigid hull inflatable boat. Observations of boat operator behavior around the whales, as well as the interpretive content of the tours was noted. Similar information was gleaned from observations noted by this researcher during a six day commercial ocean kayaking tour in Johnstone Strait, as well as two multi-day private kayak trips in the area.

\subsubsection{Compliance Survey}

The survey was intended to assess the operators' perceptions and beliefs about the utility of the code in encouraging responsible behaviour. It was also designed to help determine ways of encouraging on-going compliance to the code guidelines on a voluntary basis.

The primary objectives of the survey were to assess the code of conduct against compliance literature criteria. More specifically: the different kinds of 
sanctions that exist for the operators; the likelihood that noncompliance to the code would be detected; the likelihood of being sanctioned for noncompliance; and the perceptions and beliefs toward the utility of the code.

Suroey design

The survey instrument design was based on issues identified in the literature review; personal experiences of the researcher and informal interviews with tour operators (Appendix 2). The survey instrument consisted of three main thematic areas of investigation: perceived sanctions, beliefs and perceptions and perceived utility. It contained 41 questions.

The first thematic area of questioning, perceived sanctions, was covered in questions 1.1 through 1.9. These questions were designed to measure the effective utility, certainty, and severity of perceived sanctions. The literature on deviant behavior, and in particular social control theory, argues that the type of sanction significantly effects normative behavior (Hirschi, 1969; Williams and Hawkins, 1989; Grasmick and Bursik, 1990). Given this theory, a list of potential sanctions was developed through the literature review and interviews with tour operators. The list contained possible instrumental sanctions, such as suspension from tour operator association and exclusion from the whale-sighting network. Operators indicated the utility of the different types of perceived sanctions by rating their relative effectiveness. 
The responses were rated on a five-point Likert-type scale, and were anchored by response category extremes ranging from very effective (5) to very ineffective (1).

Certainty of being caught for code violations was measured by the operators' beliefs about the likelihood of detection for noncompliant code practices. The tour operators were asked to indicate the likelihood of detection for noncompliant code practices. The operators were then asked to indicate the likelihood of being penalized with sanctions. These two items were rated on a five-point Likert-type scale, and were anchored by response category extremes ranging from very likely (5) to very unlikely (1).

The severity of the perceived sanctions was measured through a series of questions relating to the severity of disruption the normative sanctions would bring upon operators. The questions covered a range of self-imposed (personal guilt and shame) and peer-inflicted sanctions (embarrassment, loss of respect). These questions were rated on a five-point Likert-type scale, and were anchored by response category extremes ranging from not at all (5) to very guilty/disruptive (1).

Questions 2.1.1 through 2.1.12 attempted to measure the beliefs operators' had of the code. Simply accepting the general concept of a code of conduct to encourage compliance of guidelines may not be enough to motivate operators 
to comply with all code guidelines. Consequently, operators were asked to indicate the extent to which they agreed or disagreed with statements regarding reasons for compliance with the code. The responses to this category of variables were obtained by asking the operators to circle their responses on a five point Likert-type scale from category extremes ranging from strongly agree (5) to strongly disagree (1).

Question 3.1.1 through 3.2.5 were concerned with the perceived utility of the code in guiding whale watching operations towards long-term environmental and economic sustainability. This section of the survey evaluated a variety of potential benefits of code compliance to the operators. The items in this section were anchored by response category extremes ranging from low (1) to high (5).

The final question was open ended and asked for further comments on how the code of conduct might be more effective with respect to protecting the ecology of the area.

Sample selection and suroey distribution

The number of whale watching operators in Johnstone Strait varies from season to season from ten to sixteen. There seems to be a core of operators that conduct tours every year on a regular basis (per com Borrowman, 1994). 
consent to participate in the survey. Some of the businesses contacted were major operators in the area (more than 100 days on the water/season) and some were very minor (less than 10 days on the water/season). All ten operators consented to participate in the survey. They were faxed the survey immediately following the telephone call. It was requested that personnel familiar with the code of conduct and responsible for day-to-day operations on the water complete the survey.

Cover letters were attached to the survey. These letters included a telephone number to call for further information, an assurance that results would be kept confidential, and a statement that the findings would be made available to the whale watching operators.

\subsection{Survey Analysis}

The survey analysis focuses on helping to answer three key questions: Does the code have utility to the operators?; what type of compliance "incentive measures" work best to ensure compliance?; and how could the code be improved?

In total, 10 completed questionnaires were received. Due to the size of the sample, simple frequency descriptions were used to analyze all responses. No other quantitative analysis was performed on the survey data. Interpretation 
of the data findings was based on the internal consistency of the data, personal experience, informal interviews and the relevant literature. The response patterns of the survey are described through average overall responses, item by item. 


\section{CHAPTER FOUR: FINDINGS}

\subsection{Case Study Context}

This chapter presents the results emanating from the case study and compliance survey. This chapter has four sections. The first section provides a description of the process involved in the development of the code of conduct assessed in this study. This community-based and voluntary code development process illustrates the critical importance of community involvement and site-specific guidelines for different code application situations/areas.

The second section presents the results of the compliance survey. This section is separated into three subsections describing operator responses to issues related to:

I) perceived sanctions and compliance;

ii) beliefs and perceptions toward code guidelines;

iii) the efficacy of the code guidelines in encouraging environmental stewardship.

The results of the survey relating to the efficacy of the code guidelines in encouraging environmental stewardship is discussed in section three. The chapter concludes by drawing these sections together in a discussion of the findings. 


\subsection{Development of the Code of Conduct}

\subsubsection{Management context}

The whale watching industry developed in Johnstone Strait primarily due to the exceptional orca viewing opportunities in that area. Orcas now support a multi-million dollar tour industry on Northern Vancouver Island (Duffus and Dearden, 1989). Tours operate out of Port McNeil, Telegraph Cove, Alert Bay, Kelsey Bay, Campbell River, and Vancouver (Fig. 4.1). Approximately 13 operators using vessels ranging from kayaks, sailboats, high-powered Zodiacs to 20 meter specialized whale watching boats, took more than 30,000 people annually to view orcas in 1996 (per com Borrowman, 1996).

The number of recreational boaters and kayakers visiting the area to observe whales continues to grow. Cruiseships and in-transit boat traffic now include the possibility of whale watching on their itinerary. The large ships often divert off their normal courses for better viewing of whales (per com Arcese, 1996). Sportfishers are also attracted to whale watching, and frequently stop fishing to follow the whales.

To lessen the potential of disrupting the normal behavior of the orcas in Johnstone Strait, the federal and provincial governments have taken several 


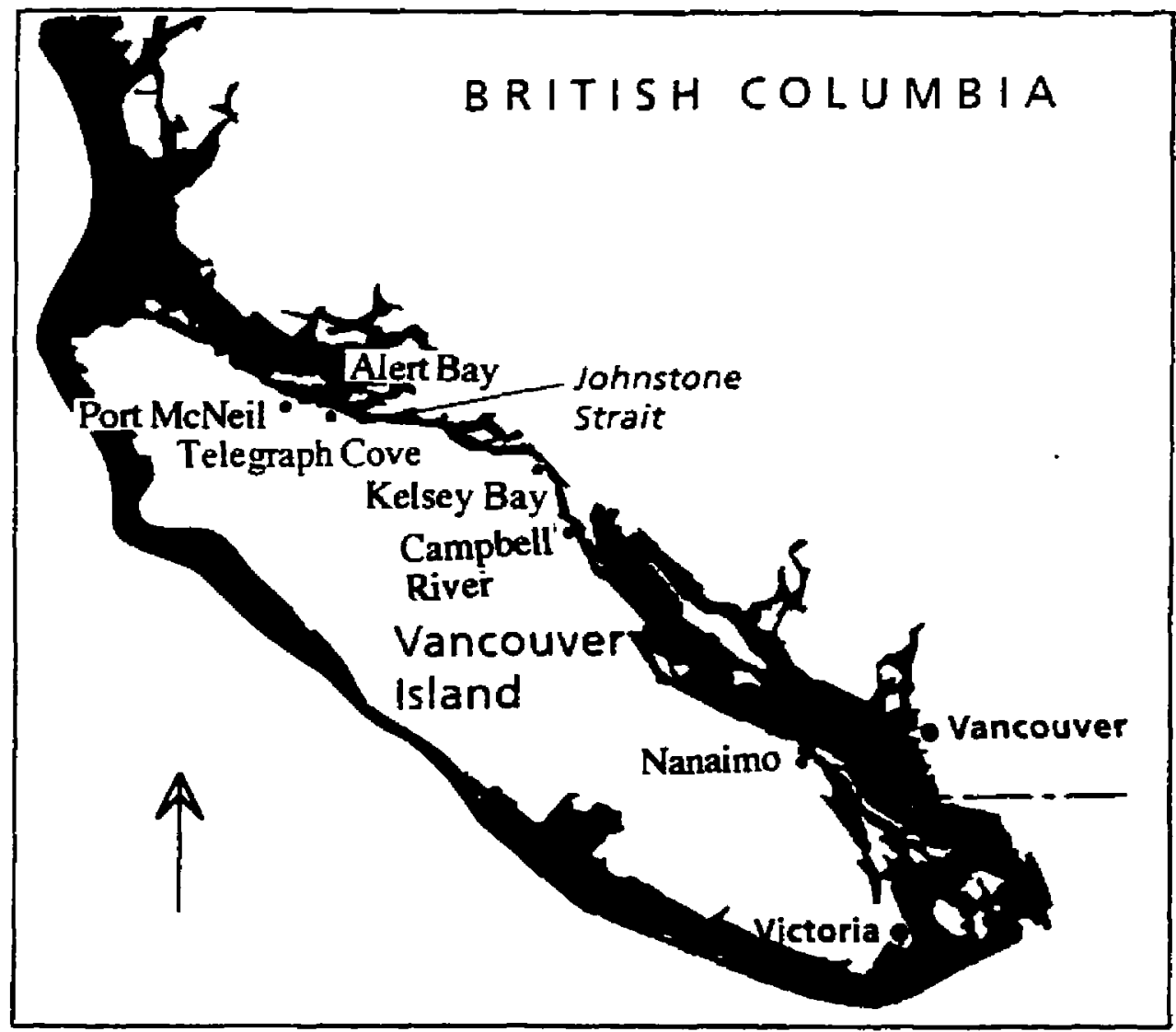

Figure 4.1 Southern Inside Passage, B.C.

measures to reduce boat traffic around whales. In particular, DFO and the MOELP have distributed whale watching guidelines to whale watchers, (e.g. whale researchers, tour operators, recreational boaters, and photographers). A MOELP warden is in place since the establishment in 1996 of RBMBER as a class A provincial park. The warden is there to inform boaters of the conservation goals of the park and to encourage visitors to respect the use prohibitions established for this park (e.g. traveling into the marine portion of the park, or landing on the beach). 


\subsubsection{Development process}

The Johnstone Strait code of conduct was developed to guide the whale watching behavior of these tour operators on a day-to-day basis. It was developed over a two year period, and involved several consensus building stages. The approach used to develop the Johnstone Strait code of conduct is summarized in Table 4.1.

\section{Table 4.1 Code Development Framework}

\begin{tabular}{|l|l|}
\hline Steps & Description \\
\hline 1. Operator workshop & $\begin{array}{l}\text { Concern for future growth of the industry. Identified } \\
\text { key management issues. }\end{array}$ \\
\hline 2. Rank issues & $\begin{array}{l}\text { Ranking helped identify the elements of the code } \\
\text { and what the management objectives should be. }\end{array}$ \\
\hline $\begin{array}{l}\text { 3. Community } \\
\text { consensus }\end{array}$ & $\begin{array}{l}\text { Important for all operators to be involved and in } \\
\text { agreement of the code guidelines. Local ownership } \\
\text { of the code by operators would be critical to its } \\
\text { success. }\end{array}$ \\
\hline 4. Draft code & $\begin{array}{l}\text { Design, format and content must meet the needs of } \\
\text { the tourism operations in the area. }\end{array}$ \\
\hline 5. Presentation of code & $\begin{array}{l}\text { Researchers educators and other area operators were } \\
\text { invited to comment on the developing code. The } \\
\text { broader group added technical knowledge, and } \\
\text { management experience to the code. Encourages } \\
\text { broader use. }\end{array}$ \\
\hline $\begin{array}{l}\text { 6. Final consensus and } \\
\text { signatory document }\end{array}$ & $\begin{array}{l}\text { All operators meet to agree on code guidelines and } \\
\text { sign-off on the written code. Code is circulated to all } \\
\text { operators and made available to others through the } \\
\text { Ministry of Small Business, Tourism and Culture. }\end{array}$ \\
\hline 7. Compliance survey & $\begin{array}{l}\text { The survey was used to evaluate the utility of the } \\
\text { code to the operators after three seasons of use. }\end{array}$ \\
\hline
\end{tabular}

Source: Gjerdalen, G. Centre For Tourism Policy and research. Johnstone Strait Code of Conduct, 1993. 
The process was designed to create a set of guidelines which were specific to the Johnstone Strait area, as well as acceptable to the operators. Because of the involvement of the community of operators involved in its development, local ownership of the code, and subsequent commitment to its guidelines was high at the time the code was developed. Table 4.2 provides a summary of the management issues identified in the code, and the guidelines developed to address these issues.

Through discussion with whale watching operators from the Johnstone Strait area, a list of management issues was developed (Table 4.2). Identifying management issues in the beginning stages of code development is very useful. The issues can guide the direction of development and help to identify code objectives. The ranking of importance of management issues for the whale watching operators appeared as shown in Table 4.2. 
Table 4.2 Whale Watching Management Issues

\begin{tabular}{|l|l|}
\hline $\begin{array}{l}\text { Management } \\
\text { issue }\end{array}$ & \multicolumn{1}{|c|}{ Description } \\
\hline $\begin{array}{l}\text { 1. Operator } \\
\text { Behavior }\end{array}$ & $\begin{array}{l}\text { The operators hold the welfare of the whales in high } \\
\text { regard. The operation of their boats should respect the } \\
\text { whales and other vessels in the vicinity. }\end{array}$ \\
\hline 2. Safety & $\begin{array}{l}\text { Adoption of the highest degree of responsible operations } \\
\text { is desired. Recommendations in the code include: } \\
\text { meeting all Canadian Coast Guard standards, and First } \\
\text { Aid training for the crew. }\end{array}$ \\
\hline 3. Professional & $\begin{array}{l}\text { This code acknowledges the need to develop and } \\
\text { disseminate knowledge of the area's natural and } \\
\text { cultural history. Leadership abilities were identified as } \\
\text { essential to the satisfaction of the clients. }\end{array}$ \\
\hline 4. Communication & $\begin{array}{l}\text { The operators acknowledge the need for open } \\
\text { communication to foster trust and co-operation between } \\
\text { themselves. This was seen to be vital to safety and } \\
\text { customer satisfaction. }\end{array}$ \\
\hline 5. Cultural Sites & $\begin{array}{l}\text { The operators acknowledge the importance of } \\
\text { co-operation with First Nations to ensure healthy } \\
\text { relations and to preserve the sites for the future }\end{array}$ \\
\hline 6. Camping & $\begin{array}{l}\text { Concern for the deterioration of the limited number of } \\
\text { campsites is acknowledged in the code. Stewardship } \\
\text { guidelines include packing out all garbage, techniques } \\
\text { for human waste disposal, and campfire restrictions. }\end{array}$ \\
\hline 7nvolvement & $\begin{array}{l}\text { Tourism operations can form an important link with } \\
\text { the local economy. Operators will attempt to involve } \\
\text { the local communities in aspects such as purchasing } \\
\text { supplies and hiring locally. }\end{array}$ \\
\hline
\end{tabular}

A code should attempt to respond to tourism's link to the environment through responsible guidelines. Once adopted, codes should remain dynamic and flexible to meet changes within the industry and the resources the whale watching operators rely upon. The Johnstone Strait code of conduct has been in use since May, 1993, and thus this research is designed to assess the code's effectiveness in encouraging responsible operations. 


\subsection{Survey Results}

This section presents the findings emanating from the operator survey. The overriding purpose of this survey was to evaluate the utility of the Johnstone Strait code of conduct for commercial whale watching operations. The specific objectives of this survey were to evaluate the utility of the code in encouraging compliance to agreed upon guidelines, and to determine operator perceptions of the most effective methods of encouraging compliance. The survey collected three types of data relating to the objectives described in chapter three. Specifically, the survey generated information about the following: perceived sanctions and compliance; beliefs and perceptions toward code guidelines; and the efficacy of the code guidelines in encouraging environmental stewardship. The findings are organized around these three themes.

\subsubsection{Instrumental sanctions}

Commercial tour operators were asked to indicate how effective or ineffective different types of sanctions might be in keeping tour operators from violating code guidelines (Table 4.3). While operators rated direct legal sanctions as the most effective form of instrumental sanction (average $=3.4$ ), two nonlegislated instrumental sanctions were also believed to be effective 
(average $=3.1$ ). These informal instrumental sanctions included exclusion from the Johnstone Strait whale-sighting network and publicizing the names of noncompliers. The operators indicated that neither suspension from the local tour operator association (average $=2.5$ ), nor publicizing the names of compliers (average $=2.7$ ) would be effective means of instrumental sanctions.

Table 4.3 Comparative Effectiveness of Different Types of Sanctions

\begin{tabular}{|l|c|c|c|c|c|c|}
\hline & \multicolumn{6}{|l|}{ Effectiveness Scores } \\
\hline Instrumental Sanctions & 1 & 2 & 3 & 4 & 5 & Average \\
\hline & 2 & 1 & 2 & 1 & 4 & 3.4 \\
\hline Exclusion from whale sighting network & 1 & 4 & 1 & 1 & 3 & 3.1 \\
\hline Publicizing the names of noncompliers & 2 & 1 & 2 & 4 & 1 & 3.1 \\
\hline Publicizing the names of compliers & 2 & 3 & 1 & 4 & 0 & 2.7 \\
\hline Suspension from tour operator association & 2 & 3 & 3 & 2 & 0 & 2.5 \\
\hline
\end{tabular}

Scale: $1=$ very ineffective, 2 =relatively ineffective, $3=$ uncertain, $4=$ effective, $5=$ very effective

\subsubsection{Normative Sanctions}

The perceived certainty of punishment was measured through operators' beliefs about the certainty of detection and the likelihood of receiving a penalty (Table 4.4). While the likelihood of detection for noncompliant code practices was felt to be very high (average $=4.4$ ), operators also indicated that the certainty of receiving a penalty was low (average $=2.5$ ). 
Table 4.4 Perceived Certainty of Punishment

\begin{tabular}{|l|c|c|c|c|c|c|}
\hline & \multicolumn{7}{|l|}{ Importance Scores } \\
\hline & 1 & 2 & 3 & 4 & 5 & Average \\
\hline Likelihood of detection & 0 & 0 & 0 & 6 & 4 & 4.4 \\
\hline Likelihood of penalty & 3 & 3 & 3 & 1 & 0 & 2.5 \\
\hline
\end{tabular}

Scale: 1=very unlikely, 2=unlikely, 3=uncertain, 4=likely, 5=very likely

Of all the potential types of normative sanctions probed, the operators perceived that the severity of self-imposed and peer-inflicted sanctions for violations of norms to be very high (Table 4.5). Respondents believed that personal guilt was the most effective normative sanction (average $=4.7$ ). Personal disruption, shame, embarrassment, and loss of respect were also perceived by survey respondents to be effective normative sanctions (average $=4.0+$ ). As well operators indicated that severe business disruption would occur as a result of code violations (average $=3.7$ ). It was indicated by respondents that normative sanctions would cause some loss of respect from peers, thereby creating personal problems (average $=3.3$ ). 
Table 4.5 Perceioed Severity of Self-imposed Sanctions

\begin{tabular}{|l|c|c|c|c|c|c|c|}
\hline Normative Sanctions & \multicolumn{6}{|l|}{ Effectiveness Scores } \\
\hline & 1 & 2 & 3 & 4 & 5 & Average \\
\hline Personal guilt & 0 & 1 & 0 & 4 & 5 & 4.7 \\
\hline Personal disruption & 0 & 1 & 0 & 5 & 4 & 4.2 \\
\hline Shame/ Embarrassment & 0 & 1 & 2 & 3 & 4 & 4.0 \\
\hline Loss of respect from significant others & 0 & 1 & 1 & 4 & 4 & 4.0 \\
\hline Business disruption & 1 & 0 & 2 & 5 & 2 & 3.7 \\
\hline Loss of respect creates personal problems & 0 & 1 & 6 & 1 & 2 & 3.3 \\
\hline
\end{tabular}

Scale: $1=$ not at all, $2=$ somewhat, $3=$ a little, $4=$ severe, $5=$ very severe

\subsubsection{Beliefs and perceptions toward code guidelines}

Survey participants were asked to indicate the extent to which they agreed or disagreed with statements regarding their reasons for compliance with the code (Table 4.6). Of the twelve statements that operators were asked to agree or disagree with, nine statements received overwhelming support, with average scores ranging from 4.0 to 4.9 . Operators stated that codes of conduct were more effective than government regulations in encouraging compliance to a set of established whale watching guidelines (average $=4.1$ ). Operators believed that it was their duty to follow the code guidelines, as nature and the community would benefit (average $=4.9$ ). Compliance to the code among all operators was high (average $=4.6$ ), with the operators supporting the code as a 
fair and appropriate management tool (average $=4.1$ ). Survey informants claimed that the rewards of compliance exceeded the costs (average $=4.7$ ). The results of this survey show some uncertainty among the operators in regard to the code of conduct increasing business (average $=2.7$ ).

Table 4.6 Comparative Importance of Beliefs and Perceptions

\begin{tabular}{|l|c|c|c|c|c|c|}
\hline Comparative Importance & \multicolumn{5}{|l|}{ Importance Scores } \\
\hline & 1 & 2 & 3 & 4 & 5 & Average (x) \\
\hline $\begin{array}{l}\text { Operators duty to follow guidelines, to } \\
\text { benefit nature }\end{array}$ & 0 & 0 & 0 & 1 & 9 & 4.9 \\
\hline Individual compliance to guidelines & 0 & 0 & 0 & 2 & 8 & 4.8 \\
\hline $\begin{array}{l}\text { Operators duty to follow guidelines, to } \\
\text { benefit community }\end{array}$ & 0 & 0 & 0 & 2 & 8 & 4.8 \\
\hline Rewards exceed costs & 0 & 0 & 1 & 1 & 8 & 4.7 \\
\hline Other operators comply with guidelines & 0 & 0 & 0 & 4 & 6 & 4.6 \\
\hline Failure to comply is unacceptable & 0 & 1 & 1 & 4 & 4 & 4.1 \\
\hline Appropriate for individual operations & 0 & 0 & 2 & 5 & 3 & 4.1 \\
\hline $\begin{array}{l}\text { More effective than government } \\
\text { regulations }\end{array}$ & 1 & 1 & 1 & 4 & 3 & 4.1 \\
\hline Code is fair to all operations & 0 & 2 & 1 & 2 & 5 & 4.0 \\
\hline Failure to comply is morally wrong & 1 & 1 & 1 & 5 & 2 & 3.6 \\
\hline Possible to practice all guidelines & 0 & 1 & 4 & 3 & 2 & 3.6 \\
\hline Has the Code Increased business & 2 & 0 & 7 & 1 & 0 & 2.7 \\
\hline
\end{tabular}

Scale: $1=$ strongly disagree, $2=$ disagree, $3=$ uncertain, $4=$ =agree, $5=$ strongly agree 


\subsubsection{The efficacy of the code guidelines in encouraging environmental stewardship}

This section describes tour operator's perceived utility of the code in guiding operations towards long-term environmental sustainability. More specifically it outlines how the operators felt about a variety of potential benefits to be derived from code compliance (Table 4.7). Overall the code of conduct was perceived to be very effective in helping operators to understand each other and to incorporate conservation messages in their operations (average $=4.4$ ). Survey respondents indicated that the written code of conduct was a very effective educational tool regarding whale watching visitors (average $=4.2$ ). As well, the code of conduct was also believed to promote a more positive public image in the marketplace. The operators indicated that an important long-term benefit of the code was its ability to encourage communication between operators and facilitate the discussion of new ideas (average $=3.8$ ). While the code's ability as a tool to regulate commercial whale watching boat behavior around whales was claimed to be high (average $=3.9$ ), it was also felt that its influence on other boat traffic was not as effective (average $=3.0$ ). 


\begin{tabular}{|l|c|c|c|c|c|c|}
\hline Potential Benefits & \multicolumn{6}{|l|}{ Effectiveness Scores } \\
\hline & 1 & 2 & 3 & 4 & 5 & Average \\
\hline $\begin{array}{l}\text { Increases understanding } \\
\text { among operators }\end{array}$ & 0 & 0 & 1 & 4 & 4 & 4.4 \\
\hline $\begin{array}{l}\text { Encourage conservation } \\
\text { message }\end{array}$ & 0 & 0 & 0 & 6 & 4 & 4.4 \\
\hline $\begin{array}{l}\text { Educating clients about } \\
\text { responsible stewardship }\end{array}$ & 0 & 0 & 2 & 3 & 5 & 4.2 \\
\hline $\begin{array}{l}\text { Regulate boat behavior } \\
\text { around whales }\end{array}$ & 0 & 0 & 2 & 7 & 1 & 3.9 \\
\hline $\begin{array}{l}\text { Encourage discussion } \\
\text { and new ideas }\end{array}$ & 0 & 1 & 4 & 0 & 5 & 3.8 \\
\hline $\begin{array}{l}\text { Increase positive public } \\
\text { image }\end{array}$ & 0 & 0 & 1 & 3 & 4 & 3.3 \\
\hline $\begin{array}{l}\text { Encouraging a culture of } \\
\text { communication }\end{array}$ & 0 & 0 & 5 & 2 & 2 & 3.3 \\
\hline $\begin{array}{l}\text { Increase quality of } \\
\text { experience to clients }\end{array}$ & 0 & 3 & 2 & 2 & 2 & 3.1 \\
\hline Influencing other boat traffic & 3 & 1 & 1 & 3 & 2 & 3.0 \\
\hline $\begin{array}{l}\text { Elevating moral conscience } \\
\text { of operators }\end{array}$ & 0 & 3 & 3 & 2 & 2 & 3.0 \\
\hline
\end{tabular}

Scale: 1=Low efficacy, 2=relatively low efficacy, 3=uncertain, 4= effective, $5=$ High efficacy

\subsubsection{The efficacy of the code guidelines in achieving stewardship}

This section of the survey asked operators to rate the degree to which they agreed or disagreed with the code's effect on achieving environmental stewardship (Table 4.8). The operators felt strongly (average $=4.2$ ) that the code of conduct was an effective voluntary approach to regulating human behavior in the whale watching environment. There was strong agreement (average $=4.5$ ) among survey participants, that the code confirmed the intentions of tour operators to operate ethically and with appropriate sensitivity to the ecology of the area. Indeed, the efficacy of the code in 
helping to ensure a long-term commitment to sustaining the area's ecological integrity was felt to be very high (average $=4.4$ ). Operators indicated that developing and utilizing the code of conduct also helped them feel like they were working together for some common good (average $=3.7$ ). For them, it provided some optimism about the future of the whales and whale watching in Johnstone Strait (average $=3.9$ ).

Table 4.8 Efficacy in Achieving Stewardship

\begin{tabular}{|l|c|c|c|c|c|c|}
\hline Stewardship Achievement & \multicolumn{6}{|l|}{ Effectiveness Scores } \\
\hline Confirms intentions of operators & 0 & 0 & 0 & 5 & 5 & 4.5 \\
\hline Helps long-term commitment & 0 & 0 & 1 & 4 & 5 & 4.4 \\
\hline Effective voluntary approach & 0 & 0 & 2 & 4 & 4 & 4.2 \\
\hline Helps optimism of future & 0 & 0 & 3 & 4 & 3 & 3.9 \\
\hline $\begin{array}{l}\text { Creates solidarity towards } \\
\text { sustainability }\end{array}$ & 1 & 0 & 2 & 4 & 3 & 3.7 \\
\hline
\end{tabular}

Scale: 1 =strongly disagree, $2=$ disagree, $3=$ neutral, $4=$ agree, $5=$ strongly agree

\subsection{Discussion of Findings}

This discussion focuses on explaining the three thematic sets of responses explored in the compliance survey. Specifically, it elaborates on issues related to: perceived sanctions and compliance; beliefs and perceptions toward code guidelines; and the efficacy of the code guidelines in encouraging 
environmental stewardship. These elaborations are based on this author's personal observations and interviews with the area's tour operators.

\subsubsection{Perceived sanctions and compliance}

The whale watching tour operators have developed a set of social norms over years of conducting theory businesses in Johnstone Strait. Through a social learning process, these norms have been internalized to the point where they become the moral standards for guiding tour operations. These social norms have evolved amongst the operators while working together in the whale watching environment. For many years these social norms were unwritten until the code of conduct was developed. The written code is in fact a manifestation of their previously informal social norms, which now clearly suggests how operators should behave. It has become a powerful tool in encouraging environmental stewardship amongst longtime and more recent entrants into the area's whale watching industry.

The compliance survey found that all of the operators believed that the likelihood of detection of normative violations of the code was quite high (Table 4.2). When the orcas are in Johnstone Strait, most of the operators know of their location through an informal whale-sighting network that they have created. It is therefore rare for a boat observing whales to be out of sight of the other boats. The likelihood of detection for code violations is therefore 
very high due to this watchdog effect. Conversely, the survey found that the likelihood of receiving a penalty for violating the norms outlined in the code was low (Table 4.2). In interpreting this finding it is useful to draw upon the relevant legislature and the key-informant interviews conducted during this research. There is no existing legislation regarding appropriate boat behavior around the orcas. When a Johnstone Strait whale watching operator was detected harassing orcas in the past, the individual was not penalized through official sanctions. As a result of this incident, many of the operators have very little confidence in the weight of official sanctions coming into play in their area.

Support for legal sanctions in this case is conditional on credible and enforceable legislation actually existing. To date, a legal description of harassment of whales has not been formulated by DFO. As well the complexity of legislation and jurisdictions affecting marine environments in Canada makes such sanctions an unrealistic option most cases. While survey respondents indicated some support for having effective legal sanctions in place, three types of instrumental sanctions were believed to also be effective: exclusion from the whale sighting network( peer-inflicted); and publicizing names of compliers and noncompliers (self-imposed) (Table 4.1).

The compliance survey found three main reasons why the utility of these instrumental sanctions was high. The first reason was moral obligation 
strengthened by the knowledge of the negative consequences of certain actions. Operators stated that the perceived severity of the peer-inflicted and self-imposed sanctions added to the potential utility of these instruments. Survey respondents indicated they would feel very guilty for not following the guidelines outlined in the code (Table 4.3). Personal and business disruption, shame , embarrassment, and loss of respect from significant others, were all perceived by the operators to be very severe consequences for non-code compliance.

A second reason for the utility of normative sanctions being rated so highly was related to a need for social inclusion. Most people have a strong desire to please others and in turn create a sense of belonging to important reference groups. The operators believed that it was in their best interest to be an accepted member of the whale watching community. They are a tight community and depend on each other for orca sightings, safety on the water, camaraderie, and business referrals.

The resulting disruption that normative sanctions might cause to nonconforming operators is the third reason informal sanctions possess high levels of utility. The survey results indicated that operators were very serious about code compliance and that their personal guilt, shame and the potential for subsequent disruption to their personal and professional lives impacted heavily on their desire to uphold the social norms of the whale watching 
community. As a result the localized social censure in the form of instrumental and peer-inflicted sanctions, are perceived by survey participants to have powerful influence over operator behavior.

\subsubsection{Beliefs and perceptions toward code guidelines}

Simply accepting the general concept of a code of conduct may not be enough to motivate operators to comply with all identified guidelines. The operators believed that codes of conduct were more effective than government regulations in having operators follow recognized whale watching guidelines. Historically in B.C., government regulations have been ineffective in managing human behavior around orcas for the following reasons: the confusion concerning legislation and jurisdictions affecting marine environments in Canada; the lack of provincial jurisdiction; and the perceived low priority status given to managing orcas by the DFO.

Consequently, operators in Johnstone Strait have embraced codes of conduct as a voluntary approach to the management of their whale watching activities. The operators were responsible for the development and ensuing implementation of the code of conduct. Direct involvement in the codes establishment helped to ensure personal ownership of, and commitment to, the guidelines. The consensus-based decision making associated with the codes development helped ensure that it would be a fair and appropriate management tool for all operators in Johnstone Strait. The process of 
development, used the stored wisdom and insights of all operators in identifying the critical content for the guidelines. As a result, long-term commitment to code compliance, personal stewardship roles and the knowledge of the probability of personal social censure, are all incorporated into the guidelines. The ultimate result of this process is that the code of conduct benefits the orca habitat and the whale watching community.

\subsubsection{The efficacy of the code guidelines in encouraging environmental stewardship}

The code of conduct is perceived to have been very effective in helping operators understand each other and stimulate the promotion of a common conservation message in their activities. Through face-to-face meetings during the development of the code operators met collectively for the first time. These meetings helped the operators to identify common issues and appreciate individual needs. Working together towards a common goal increased the ability of the group to formulate new ideas and identify appropriate management strategies. Without this opportunity for discussion, individual operators might have continued to behave in ways they believed to be correct, without appreciation of the larger management context. Consequently, the code's development process facilitated the creation of innovative management techniques. In turn this has been perceived to have benefited not only the area's ecological integrity, but also the human community that depends on the area's natural environment. 
The operators felt strongly that the code of conduct is an effective voluntary approach for encouraging all operators to pursue their activities ethically and with appropriate sensitivity to the area's ecology. The code of conduct was seen as a very effective whale watching educational tool. Today operators use the code as a guide in explaining to visitors responsible boat and viewing behavior. The code is also a useful tool in discussing broader principles related to the welfare of the whales and the sustainability of the industry.

The efficacy of the code in helping to ensure a long-term commitment to sustaining the ecology seems to be very high. Developing and utilizing the code of conduct has helped operators feel like they are working together for the common good of the orcas and their habitat. The code has provided optimism about the future of whale watching in Johnstone Strait. 


\subsection{INTRODUCTION}

This chapter outlines potential management implications associated with the findings of the study. While the findings of the case study can not be generalized, they do, together with the literature offer a promising model concerning codes of conduct as a self-regulating management tool. The implications are directed at nature-based tour operators and tour associations. The potential utility of codes of conduct as a management tool is discussed in a marine context. However, the management implications can also be applied to terrestrial settings where there are groups of operators interested in developing and utilizing a code of conduct to guide their operations.

Those tour operators and tour associations interesting in developing a code of conduct need to take a holistic approach to environmental stewardship. The following environmental stewardship framework (Figure 5.1) has been developed to guide operators and associations in achieving this goal. The framework is based on the rationale that both resource capital and human capital need to be considered in the stewardship of natural environments. The whole framework is embedded within an environmental and user community management context. 


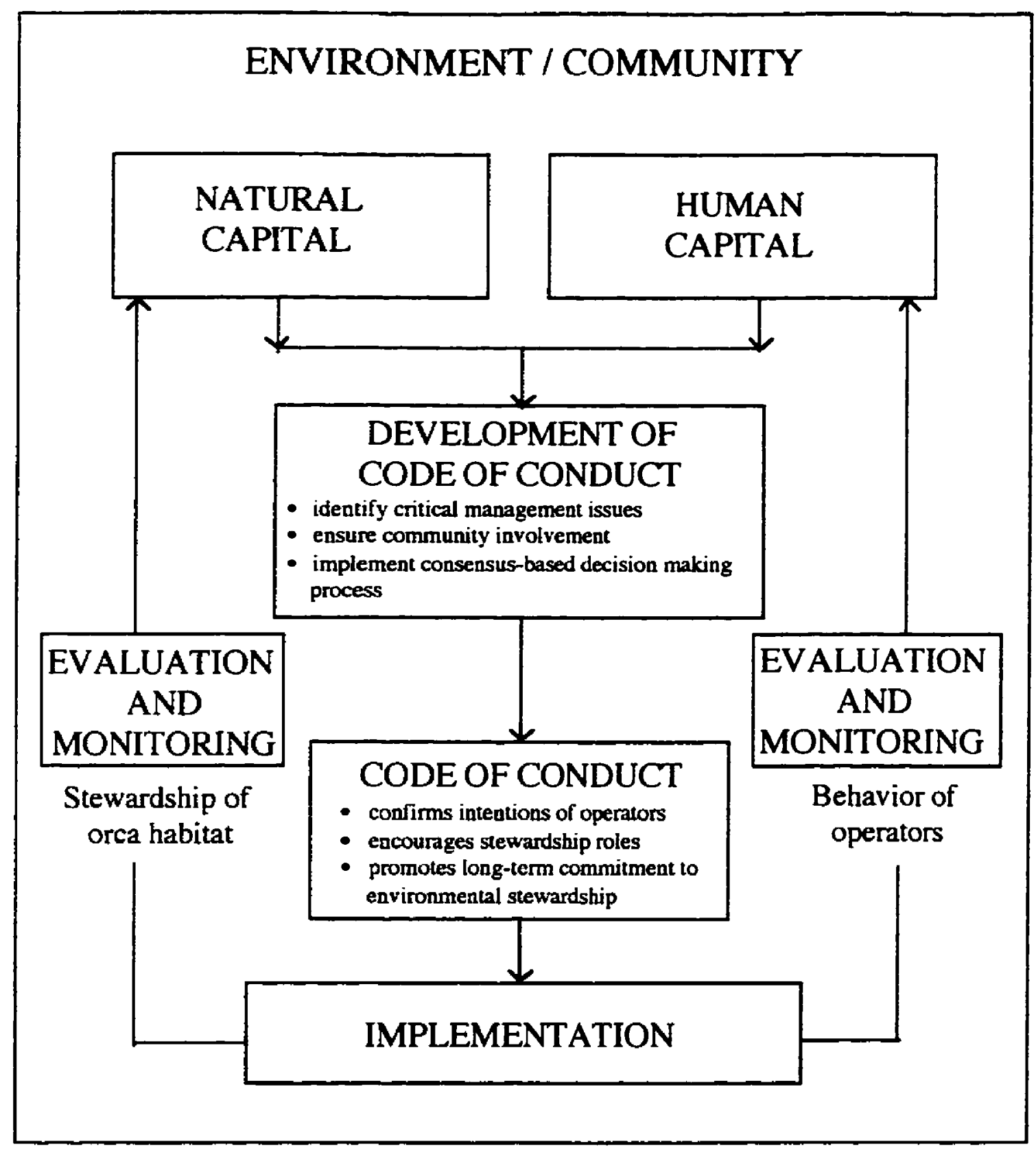

Figure 5.I Environmental Stewardship Framework

Codes of conduct in this context provide direction for the protection and use of whale watching areas such as Johnstone Strait. They can help to guide and 
regulate commercial operations. However to be effective they must be guided by a vision and associated guidelines for minimizing the impact of specific whale watching activities. This vision and subsequent guidelines should be developed with input from the community of tour operators. Face-to-face workshops/meetings designed to develop consensus on key issues and activities to be addressed are critical to the success of a code of conduct. The operators involved in the development should engage in the process of consensus-based decision making, culminating with agreement on all code elements and a formal signatory document. The actions necessary to achieve these guidelines should also be outlined. Monitoring and evaluation for both the operators and the environmental resource are needed to measure their performance. Codes of conduct are meant to be dynamic - to be adapted over time to changing circumstances, scientific understanding and changing values.

\subsection{THE ROLE OF VOLUNTARY COMPLIANCE SYSTEMS}

This study demonstrates the utility of a code of conduct as a voluntary management tool in encouraging environmental stewardship. It identifies a number of key benefits resulting from the use of a voluntary compliance system to guide and regulate whale watching operations. The following section describes some of the key characteristics of codes of conduct. 
Codes of conduct are useful in empowering local tour operators to take responsibility for environmental stewardship. Johnstone Strait is a relatively large marine environment. In this region, enforcement of legislation is both expensive and impractical, primarily because it is difficult to monitor operator behavior. A voluntary management tool, such as a code of conduct, that is used by a community of whale watching operators provides a useful management alternative. Self-chosen stewardship responsibilities help operators make a long-term commitment to responsible practices, confirm their intention to operate with integrity and provide a sense of personal control over key issues affecting their future activities. A written code of conduct also provides a framework for common understanding about their stewardship responsibilities. It encourages all code proponents to practice conservation and discuss new management approaches. By implementing a code of conduct the long-term protection of orcas is not solely dependent on expensive and impractical legislation.

\subsubsection{Managing Common Property Resources}

Mutual moral understanding is crucial where people share common property resources. It can help competing individuals better understand each other's needs. For example, by using a code of conduct as a management tool, members of the Johnstone Strait whale watching community came to an 
agreement on the tolerable, and/or intolerable forms of behavior within the natural habitats of the bioregion they conduct tours in. This common understanding has promoted the development of voluntary and consensusbased best environmental practices.

\subsubsection{Compliance to Societal Norms}

The code of conduct suggests how operators should behave. Its guidelines are a framework within which the community agrees to behave. This community-based compliance system offers an opportunity to effectively use localized social censure as a powerful deterrent to non-code activities. The community has a built-in incentive to stay well within the biological limits of the resource which have been learned by experience. The community also has at its disposal the requisite social coercive mechanisms to force compliance with expected behavior. The self-regulating system of the code allows for the watchdog effect of colleagues to encourage personal enforcement as a complement to legislated management systems.

\subsubsection{Commercial operators' role as educators}

Codes of conduct can serve to enhance the public image of commercial tour operators. Maintaining a positive public perception is important to the continuing existence and business success of operators. The credibility of the 
operators using the code may be protected through adherence to the guidelines. When operators encourage the use of codes of conduct among their employees, competitors, and visitors, they also reduce the risk of damage to the habitat and disturbance of orcas. An operator practicing responsible stewardship in the delivery of a whale watching operation may be perceived as being more credible than other practitioners in efforts to protect the resource base.

Credibility can also provide the tour operators with the opportunity to influence recreational boaters on the water, as well as to increase the professional image of the industry as a whole. Other users such as sport fishing groups and recreational boaters, may see the operators as models for their own conduct on the water. An increased positive image may also be a valuable educational and awareness-raising opportunity for whale watching operators. Recreational boaters are often poorly informed about the potential effects of their actions on whales. With their fast, maneuverable crafts, recreational boaters have been known to make a game of pursuing and harassing whales. Whale watching charter operators can contribute to the education of recreational boaters regarding the importance of Johnstone Strait to orcas. They can also inform pleasure boaters on the use of appropriate whale watching techniques. These pleasure boaters often follow the lead of the commercial operators in hopes of viewing the whales (per com Borrowman, 1995). Thus, a well designed and carefully developed code of 
conduct may add power to the tour operators' ability to influence the behavior of other user groups in the area.

Twenty years ago the commercial fishers on the coasts of B.C. shot orcas. Today, through communication with tour operators and whale researchers, the attitude of commercial fishers has changed to that of appreciating the whales. During an interview, whale watching tour operator, Bill McKay, provided an example of this changed attitude. He had shared his hydrophone with an influential Chief of a local First Nation in Johnstone Strait with the intention of enlightening the chief to the sophisticated vocalization of the whales. The experience of listening to the whales communicating underwater was so powerful for the chief that the native leader took it upon himself to influence his band members' traditional view of the whales as hostile competitors for salmon (per com McKay, 1993). Instead of harassing the orcas, these fishers now have greater understanding of the orcas and in turn treat them with more respect.

\subsubsection{Educational tool for new operators}

This study suggests that the learning curve for new operators entering the whale watching sector may be accelerated as the result of awareness of a written code of conduct. The code of conduct, as an educational initiative, increases consistency in the delivery of whale watching products and services. 
New operators have the advantage of utilizing a clear set of guidelines that help prepare them for their day-to-day activities and guides them away from making regrettable mistakes. The "breaking-in period" for new operators is significantly decreased and undue harassment of whales may be avoided through exposure to such codes. If new operators follow the guidelines that they have agreed upon in the code, professional measures become more consistent and of a higher standard. These professional standards include safety, communication, behavior towards wildlife, and cultural sensitivity.

\subsubsection{Educational tool for visitors}

Codes of conduct may also serve the function of informing other stakeholders of the practices necessary for more sustainable use of whale watching environments. In the case where an operator is pressured to do something they morally cannot accept, the code serves to buttress the person's resolve to resist the pressure, and to provide authority for the operator's arguments against the others.

Codes of conduct may be useful in a whale watching situation where clients demand that operators get closer to the whales for better viewing purposes. In such situations the operator can use the code as an effective tool to resolve potential disagreements, and at the same time turn such conflict circumstances into educational opportunities. In the Johnstone Strait case, 
operators may want to inform their clients about the importance of maintaining key orca habitat, and the significance of not interfering with the whales ability to communicate, rest or to hunt. By stating that, whale vocalization is critical to communication and hunting, and that boat noise and disturbance can handicap the orca's ability to carry out these functions effectively, the operator can help clients learn about the cetacean and appreciate the rationale for keeping an appropriate distance between the tour boat and the orcas. Conservation objectives embodied in a code are highlighted in this way, and the whale watching public becomes exposed to the importance of sound environmental stewardship. Codes of conduct provide a tremendous opportunity to transmit conservation messages, management objectives, and the guidelines necessary to implement them.

Whale watching visitors on a tour boat are essentially a captive audience. In such contexts, audiences get the message from the tour operators themselves, either through verbal or written communication. The operator is often someone with whom visitors become familiar and perceive to have credibility. The likelihood of the visitors to natural places respecting the message and acting accordingly is increased, through the familiarity, and respect gained with the experience on a whale watching vessel.

Tour operators in Johnstone Strait feel confident in their ability to act as responsible role models partially because of the code. They feel that it plays a 
significant role in raising environmental awareness to a broad spectrum of user groups.

\subsection{Shared Evaluation and Monitoring}

Once a commitment to put a code into action is made, it is essential to measure the progress achieved and to share the results. The Johnstone Strait tour operators agreed to uphold the code in May of 1993. However, it is imperative that their performance against agreed practices be assessed and reported on a regular basis. The findings suggest this is one management area that needs to be improved upon in Johnstone Strait.

Tools such as environmental audits and total quality management approaches are acknowledged as essential components of good environmental monitoring (Todd, 1996). Monitoring can be used to measure the response, and the level of acceptance, of codes of conduct. Through monitoring, areas where implementation efforts have failed or had poor results can be identified, and appropriate remedial measures can be taken to reach the defined goals (Todd, 1996).

The Johnstone Strait charter association could take advantage of the monitoring of Johnstone Strait that MOELP has implemented. Through the use of observation techniques employed on Craycroft island in Johnstone 
Strait, researchers are recording the interactive behavior of whales and humans (Briggs, 1991b). The results of this monitoring, which address issues such as short-term whale behavior around boats, would be useful in assessing operator performance against the guidelines outlined in their code of conduct. The commercial whale watching community might use such information to assess the level of operator compliance to the code. The monitoring may also be used in assessing the efficacy of the code in terms of preserving the ecological integrity of the orca habitat. If the research shows that operators are not adhering to the code guidelines and disturbing whales, more effective solutions for compliance will have to be addressed. 


\section{CHAPTER SIX: CONCLUSIONS AND RECOMMENDATIONS}

\subsection{INTRODUCTION}

This research has demonstrated that a code of conduct for the commercial whale watching operators of Johnstone Strait has utility in guiding and regulating tour operator behavior, as well as in encouraging sound environmental stewardship. It has also identified key reasons why operators are apt to comply to such guidelines. This chapter provides overriding conclusions, as well as recommendations for further research in this area of study.

\subsection{SUMMARY OF MAJOR FINDINGS}

Three key questions related to the utility of codes of conduct have been addressed in this study. The findings are summarized in Table 6.1. The research established that operators believe that the Johnstone Strait code of conduct is a more preferred approach to regulating behavior than government legislation. Compliance to the code of conduct is ensured through an internalized set of established community norms. 
Table 6.1 Conclusions

\begin{tabular}{|l|l|}
\hline Research Questions & Conclusions \\
\hline $\begin{array}{l}\text { (1) How has the code been } \\
\text { useful to operators? }\end{array}$ & $\begin{array}{l}\text { - Confirms intentions of operators. } \\
\text { - Promotes long-term commitment to } \\
\text { environmental stewardship. }\end{array}$ \\
& $\begin{array}{l}\text { - Increases understanding among operators. } \\
\text { - Encourages conservation practices. }\end{array}$ \\
\hline $\begin{array}{l}\text { (2) How does a code } \\
\text { encourage compliance? }\end{array}$ & $\begin{array}{l}\text { - Ereates positive public image. } \\
\text { - Educates visitors about environmental } \\
\text { stewardship. }\end{array}$ \\
\hline $\begin{array}{l}\text { (3) What are the most } \\
\text { effective methods of } \\
\text { encouraging compliance? }\end{array}$ & $\begin{array}{l}\text { - Involving key stakeholders in the } \\
\text { development of the code. }\end{array}$ \\
\hline
\end{tabular}

\subsection{RECOMMENDATIONS FOR FURTHER RESEARCH}

Several areas for further research evolve from this study. They reflect management issues that have been identified as this research study evolved. 


\subsubsection{Encouragement of a commitment to the development of a code of conduct}

This study describes a framework for developing and implementing a code of conduct for whale watching tour operations. However, further research could be useful in finding ways of encouraging equal commitment to such codes by other nature-based tour operators.

\subsubsection{Identification of indicators of compliance}

Indicators of compliance to the code of conduct form an important element of assessing the efficacy of codes in guiding tour activities. Are acceptable levels of compliance indicated simply by words in brochures, or are important dimensions of compliance encouraged through voluntary audits and/or annual educational workshops?

\subsubsection{Development of criteria for code success}

Research is needed to further identify and develop critical elements essential to the success of a code of conduct. Developing criteria for code success may support normative sanctions which encourage compliance. Criteria could include: identifying critical management issues; ensuring community involvement; facilitating face-to-face meetings/workshops; implementing a 
consensus-based decision making process; and committing to ongoing evaluation and monitoring.

\subsubsection{Establishment of evaluation and monitoring}

Ongoing evaluation and monitoring of the efficacy of the code of conduct is essential to its long-term success. Mechanisms need to be established that could ensure the continued assessment of operator compliance to the code. Scientific data collected over the last decade regarding boat/orca interaction could be utilized to assess any changes to this interplay since the implementation of the code.

\subsubsection{Evaluation of the code by other stakeholders}

Evaluation of the code's utility by other stakeholder groups such as orca researchers, recreational boaters and sport fishers could broaden the implications for the use of the code. Such implications may include the biophysical perspective of the code to the stewardship of orca habitat. Another area of research could focus on the utility of the code in encouraging environmental stewardship roles for recreational boaters or sport fishers. 


\section{APPENDIX 1}

\section{JohnSTONe STRAIT CODE OF CONDUCT}

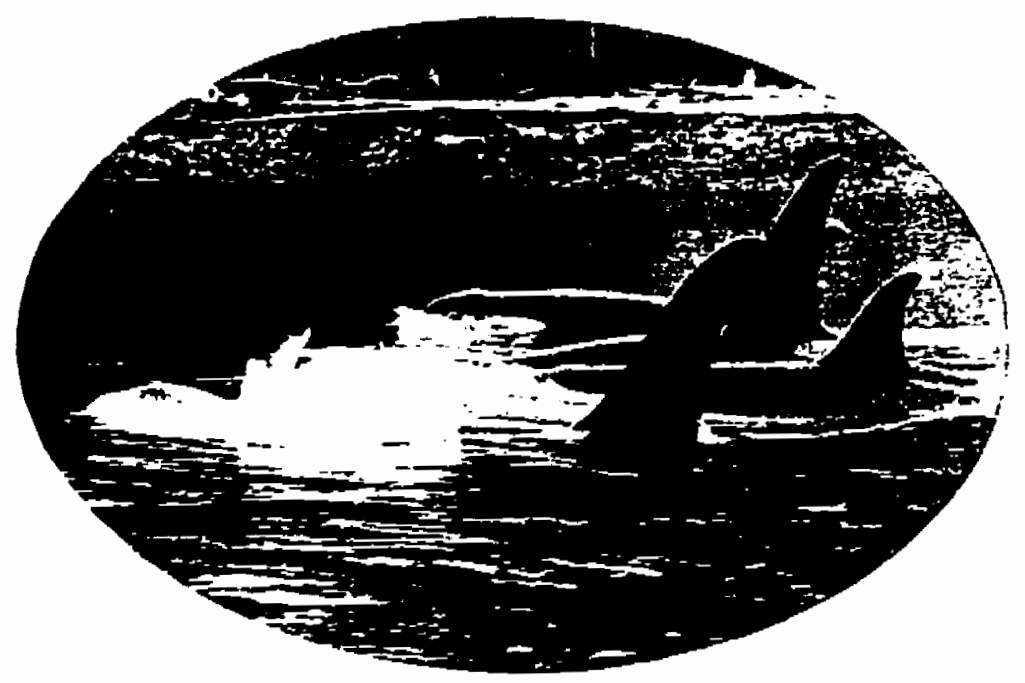

A Code Guiding Commercial

Tour Operators, Resource

Guides And Visitors

In Protecting

Johnstone Strait 


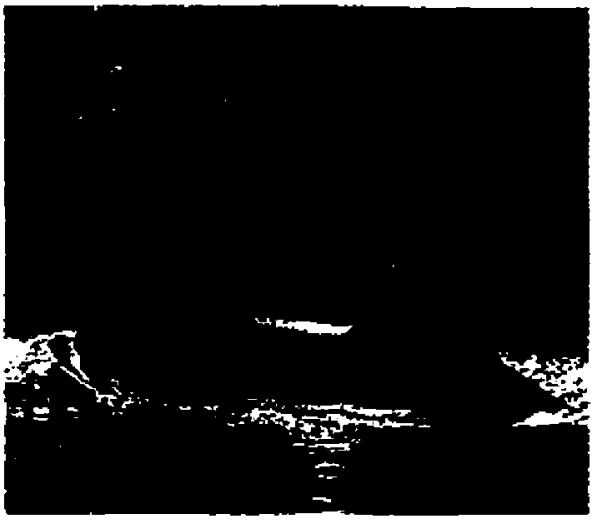

\section{Introduction}

This Code of Conduct is the result of constructive input and effort provided by a wide variety of concerned citizens. These include: commercial tour operators, professional resource guides, researchers and educators, all of whom have worked towards creating this voluntary code of conduct. It is recognized that the guidelines offered have limitations, but we believe that they demonstrate a substantial step towards enhancing responsible operations in the area. The Code is meant to be dynamic - to be adapted over time to changing circumstance, scientific understanding and changing social values.

\section{Preamble}

This Code of Conduct has been developed to ensure the safety of our clients, and to provide guidelines for minimal impact on Orcas, other wildlife and the natural habitats of Johnstone Strait. The intent of this Code is to guide and regulate our commercial operations. We also wish to inform, educate, and voluntarily involve all other visitors in the wise and sustainable use of this exceptional area. 


\section{The Code}

The Code is organized into ten sections:

Communication

Wildlife

Robson Bight Ecological Reserve

Rules for Observing Orcas

Safety

Cultural Sites

Professionalism

Camping

Local Involvement

Garbage

\section{Communication}

We acknowledge the need for open communication between operators to foster trust and co-operation, both on and off the water. Healthy communication is vital to safety and the overall success of our activities.

Therefore we will:

- Co-operate and communicate in a friendly and professional manner with other operators or parties.

- Whenever possible, communicate and co-ordinate campsite use with other parties and operators in advance of visits.

- Demonstrate and build awareness of appropriate whale watching techniques. 


\section{Wildlife}

Part of the experience for visitors may be to closely observe bird life, marine mammals and land mammals. To ensure the least intrusion and disturbance to the natural patterns and behavior of wildlife, we will approach all sighted wildlife with care and sensitivity.

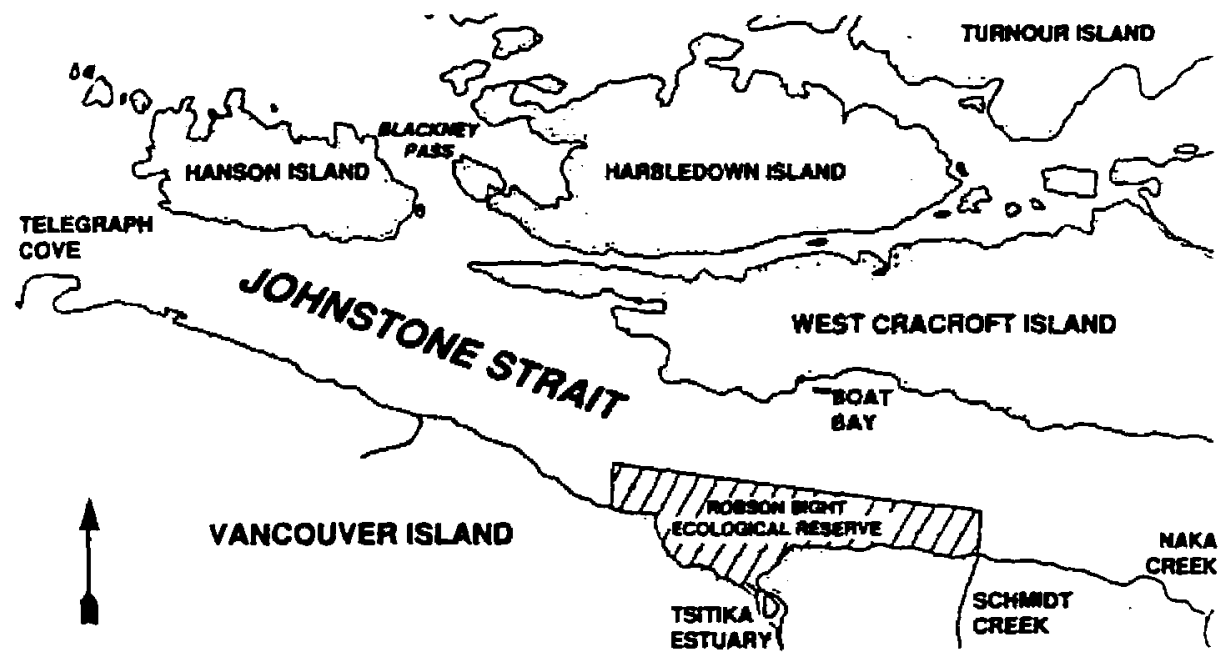

\section{Robson Bight (Michael Bigg) Ecological Reserve}

This ecological reserve was established in 1982 "... to protect key habitats for killer whales, prevent harassment while using those babitats and maintain unique opportunities to research and observe killer whales; (and) to protect a pristine estuary and forested shorelines." Robson Bight Ecological Reserve is closed to recreational traffic, and landing is prohibited in this area. Discharge of firearms is prohibited in this ecological reserve. 


\section{Code of Conduct Rules For Observing Orcas}

To protect the Orcas of Johnstone Strait from unnecessary disturbance, we will abide by the following:

- NOT ENTER THE ROBSON BIGHT ECOLOGICAL RESERVE.

- Outside the Reserve, come no closer than 100 meters of the whales.

- Approach whales from the side; not from the front or the rear. Approach and depart slowly. Avoid disturbing a "line" of resting whales.

- When paralleling whales not alter speed or change course abruptly.

- Keep noise levels down - no horns, whistles, shouting or racing of motors.

- Be conscious of the effect of actions on the whales. Not engage in any activity which will disturb or interfere with them.

Under section 71 (A) (2) of the Federal Fisheries Regulations it is illegal to disturb or molest Orcas.

- Where several operators are engaged in watching a single pod, it may be necessary to communicate with other vessels in order to not restrict the free movement of the whales. 


\section{Safety}

The marine environment of this area is unpredictable. High winds, strong currents, extreme tides and vessel traffic combine to create hazardous conditions. We encourage the adoption by all operators of the highest degree of responsible operations, vesstandards, and crew/guide training.

These include insuring that:

- All tour operators have sufficient experience to operate safely in the waters of Johnstone Strait.

- All vessels are seaworthy, well maintained, well equipped, and meet all Canadian Coast Guard (CCG) standards.

- All crew are trained in First Aid (preferably advanced), and marine emergency duties, hold radio operators' licenses, and have CCG certification where required. 


\section{Professionalism}

At all times we will conduct ourselves and our business in a professional manner. This includes:

- Demonstrating leadership, knowledge and operational skills suited to use in the waters of Johnstone Strait.

- Conducting accurate and responsible marketing.

- Recording and communicating to proper authorities (British Columbia Parks Service, Department of Fisheries and Oceans. Canadian Coast Guard) any questionable, problematic or unsafe activities.

- Engaging in professional development through the leadership and/or support of an association.

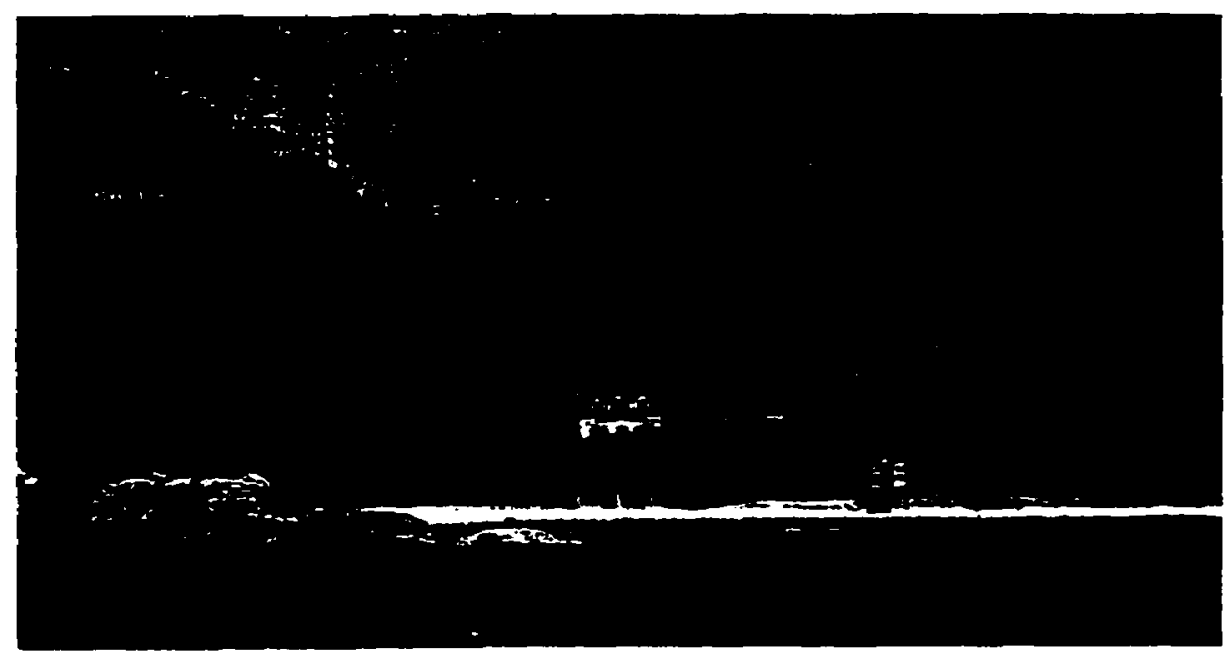




\section{Cultural Sites}

We acknowledge and respect First Nations' concerns regarding visitation to Cultural Sites. Therefore, we will:

- Not enter any Cultural Sites without obtaining prior permission from the responsible First Nations.

- Not disturb middens or remove any artifact; nor enter burial grounds; nor leave garbage or human waste at these sites.

- Not camp without permission of the First Nations.

- Not disturb cultural sites, including those outside of recognized reserves.

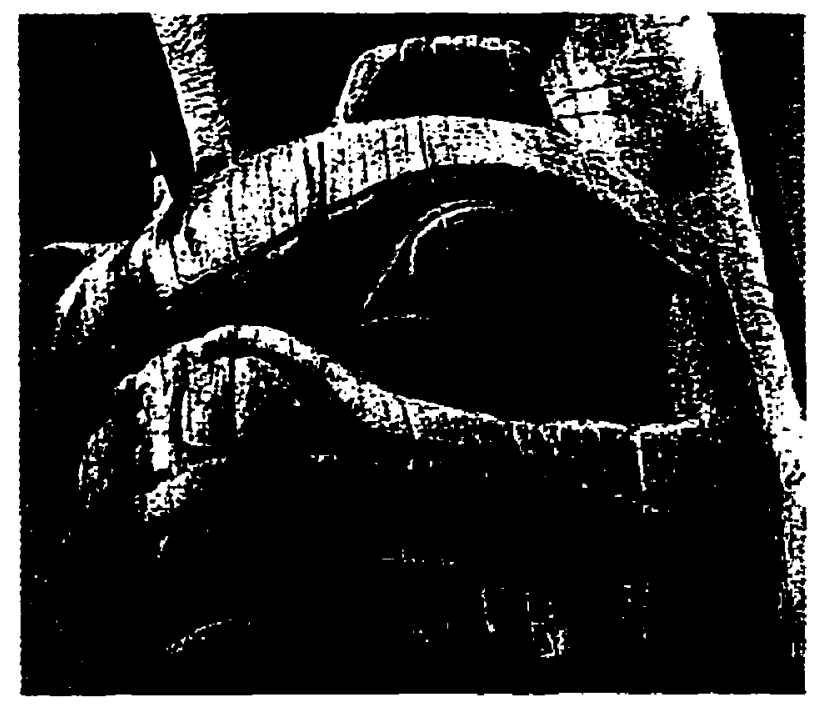




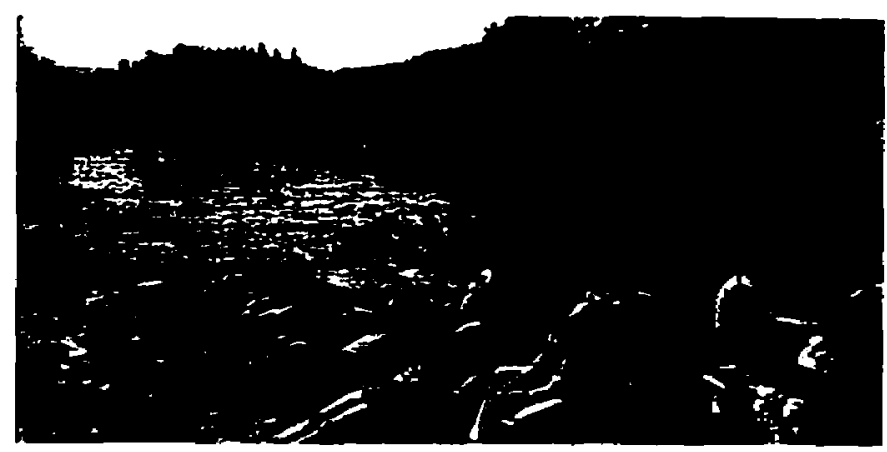

\section{Camping}

We recognize that there are a limited number of suitable campsites for the large numbers of tour groups that visit the area during peak season (June-September). To lessen the impacts of camping, we will:

- Build fires on the foreshore, below the high tide mark, and away from drift wood: make sure fires are extinguished when unattended; use only drift wood for fires.

- Where practical, use the intertidal zone for defecating. Where this is not possible, dig a pit toilet. In either situation. ensure that all toilet paper and sanitary napkins are burned or packed out.

- Not bathe upstream from the mouth's of rivers and streams Use biodegradable soaps for dishes, bathing, and laundry.

- Minimize impacts to vegetation and intertidal areas by using established path ways, minimizing destructive activities and refraining from harvesting inter-tidal life.

- Practice no trace camping (leave it as you found it), store gear unobtrusively and avoid the use of highiy visible tarps. 


\section{Local Involvement}

Recognizing the importance of sustainable activities and local involvement, we will attempt to:

- Hire local people in tour operations wherever practical.

- Buy supplies and materials locally when available.

- Improve communication between local people and operators.

- Work with local people to encourage the wise and sustainable use of the resources in the community.

\section{Garbage}

With increased visitation in Johnstone Strait by boats, aircraft, and people, there will be more garbage and human waste. We will operate utilizing "no trace" practices. Specifically, we will:

- Bum paper and organics below the high tide mark.

- Encourage the use of well-flushed, lower intertidal areas for disposal of human waste.

- Pack out all cans, plastics, bottles, non-biodegradables and biodegradables.

- Not discharge holding tanks while in anchorages. 


\section{Participants}

Constructive input concerning this Code was received from a wide variety of concerned citizens. These included:

Jim Alien*
David Arcese*
Jim Borrowman*
David Briggs
Randy Burke*
Dan Culver
Wayne Cuthbert*
Phyllis Edgar
Graham Ellis
Brian Falkoner*
john Gamble*
Colleen Gansner*
John Gansner*
Pat Gurlach*
Gabriel Lacombe
Lance Barrett Leonard
Bill McKay*
Dennis Richards*
Robin Taylor
David Towers*
Maureen Towers*

Jim Allen*

Jim Borrowman

David Briggs

Randy Burke*

Dan Culver

Wayne Cuthoert

Phyllis Edgar

Graham Ellis

Brian Falkoner

John Gamble*

Colleen Gansner*

John Gansner*

Pat Gurlach *

Gabriel Lacombe

Lance Barrett Leonard

Bill McKay*

Dennis Richards*

Robin Taylor

Maureen Towers*

\author{
Ecosummer Expeditions \\ Northem Lights Expeditions \\ Stubbs Island Charters \\ Researcher \\ Bluewater Adventures \\ Bluewater Adventures \\ C-Sea Fury Marine Lid. \\ Northern Lights Expeditions \\ Researcher \\ Maple Leaf Charters \\ Wayward Wind Charters \\ Robson Bight Charters \\ Robson Bight Charters \\ Bluewater Expeditions \\ Ecosummer Adventures \\ Researcher \\ Stubbs Island Charters \\ Viking Lodge \& Charter \\ Researcher \\ Seasmoke Sailing Tours \\ Seasmoke Sailing Tours
}

Vancouver, B.C.

Seattle, Wash.

Telegraph Cove, B.C.

Vancouver, B.C.

Vancouver, B.C.

Vancouver, B.C.

Fanney Bay, B.C.

Courney, B.C.

Nanaimo, B.C.

Vancouver, B.C.

Sointula, B.C.

Kelsey Bay, B.C.

Kelsey Bay, B.C.

Vancouver, B.C.

Vancouver, B.C.

Vancouver, B.C.

Telegraph Cove, B.C.

Port MacNeil, B.C.

Vancouver, B.C.

Alert Bay, B.C.

Alert Bay, B.C.

- Commmercial operators officially agreeing to conduct their tour operations according to this Code of Conduct. 


\section{APPENDIX 2}

\section{Iohnstone Strait Code of Conduct}

\section{Commercial Tour Operators Survey}

\section{Introduction}

The Johnstone Strait Code of Conduct provides tour operators with specific guidelines concerning how to minimize the impact of their operations on Orcas, other wildlife and the natural habitats of Johnstone Strait. A consensus concerning the guidelines for the Code was developed by most of the commercial tour operators operating in Johnstone Strait in 1993. The intention of the Code was to encourage responsible tour operations so that area's natural habitat, wildlife and tourism industry would continue to thrive. The written Code of Conduct has now been available for use for three whale watching seasons.

This survey is intended to examine the utility of the code in encouraging responsible behaviour amongst tour operators in the area. It is also designed to help determine ways of encouraging on-going compliance to the codes guidelines on a voluntary basis. 
As a member of the Johnstone Strait tour operator community, would you kindly answer the following questions. Your individual answers and comments will be kept strictly confidential. However, your information will be used in combination with that offered by other tour operators to provide an overview of how operators feel about the Code and practical strategies for effective voluntary compliance. This survey is strictly voluntary and, if you do not wish to, you do not have to answer all questions. You can also withdraw and cease to participate in this survey at any time.

This survey is being conducted by researchers associated with the Centre For Tourism Policy and Research at Simon Fraser University, and results of this research can be obtained through this Centre at Simon Fraser University, Burnaby, British Columbia, V5A 1S6. If you have any comments or complaints concerning the survey or its content, please do not hesitate to contact Dr. Frank Gobas, Director, School of Resource and Environmental Management, Simon Fraser University, Burnaby, British Columbia, V5A 1 S6. (Tel: 1-604- 291-3074). 
Please fax the completed survey to (604) 984-4993 by Nov. 12, 1996.

\subsection{Voluntary Code Compliance}

1.1 Please indicate how effective or ineffective each of the following types of sanctions might be in keeping tour operators from violating the guidelines outlined in the Johnstone Strait Code of Conduct. Please circle one number to show how you feel about the following sanctions.

\begin{tabular}{|c|c|c|c|}
\hline $\begin{array}{l}\text { Very } \\
\text { Ineffective } \\
\qquad 1\end{array}$ & $\begin{array}{l}\text { Relatively } \\
\text { Ineffective } \\
2\end{array}$ & $\begin{array}{l}\text { Uncertain } \\
3\end{array}$ & $\begin{array}{l}\text { Relatively } \\
\text { Effective } \\
4\end{array}$ \\
\hline
\end{tabular}

1.1.1 Suspension from tour operator association

1

2

3

4

5

1.1.2 Exclusion from whale- sighting network

1

2

3

4

5

1.1.3 Publicizing the names of compliers

1

2

3

4

5

1.1.4 Publicizing the names of noncompliers

1

2

3

4

5

1.1.5 Direct legal sanctions

1

2

3

4

5 
1.2 Under current conditions in Johnstone Strait please indicate the likelihood that a tour operator would be detected for noncompliant code practices. Please circle one number.

$\begin{array}{lllll}\begin{array}{l}\text { very } \\ \text { unlikely }\end{array} & \text { unlikely } & \text { uncertain } & \text { likely } & \begin{array}{l}\text { very } \\ \text { likely }\end{array} \\ \mathbf{1} & \mathbf{2} & \mathbf{3} & \mathbf{4} & \mathbf{5}\end{array}$

1.3. Under current conditions in Johnstone Strait please indicate the likelihood that a tour operator would be penalized with sanctions for noncompliant code practices. Please circle one number.

$\begin{array}{lllll}\text { very } & \text { unlikely } & \text { uncertain } & \text { likely } & \begin{array}{l}\text { very } \\ \text { unlikely }\end{array} \\ \mathbf{1} & \mathbf{2} & \mathbf{3} & \mathbf{4} & \mathbf{5}\end{array}$

1.4. To what extent might you feel personally guilty if you did not follow the guidelines outlined in the Code of Conduct. Please circle one number.

$\begin{array}{lllll}\text { not } & \text { somewhat } & \text { a little } & \text { guilty } & \text { very guilty } \\ \text { at all } & 2 & 3 & 4 & 5\end{array}$

1.5. To what extent might you feel shame/embarrassment if you didn't follow the guidelines of the Code of Conduct. Please circle one number.

$\begin{array}{lllll}\begin{array}{l}\text { not } \\ \text { at all }\end{array} & \text { somewhat } & \text { a little } & \text { shame } & \text { very } \\ \mathbf{1} & 2 & 3 & 4 & 5\end{array}$

1.6. Under current sanctions, what degree of business disruption would be created in your business if your tour operation was identified for non compliant code behavior. Please circle one number.

$\begin{array}{lllcl}\begin{array}{l}\text { not } \\ \text { at all }\end{array} & \text { some } & \text { a little } & \text { disruptive } & \begin{array}{l}\text { very } \\ \text { disruptive }\end{array} \\ \mathbf{1} & 2 & 3 & 4 & 5\end{array}$


1.7. Under current sanctions, what degree of personal disruption would be created if your operation was identified for non- compliant code behavior. Circle one number.
not
some
a little
disruptive
very
at all
1
2
3
4
disruptive
5

1.8. To what extent might your peers/family/friends lose respect for you, if your operation did not follow the guidelines of the code. Circle one number.

$\begin{array}{lllcl}\begin{array}{l}\text { not } \\ \text { at all }\end{array} & \text { some } & \text { a little } & \text { significant } & \begin{array}{l}\text { very } \\ \text { significant }\end{array} \\ 1 & 2 & 3 & 4 & 5\end{array}$

1.9. To what extent would the loss of respect from your peers create personal problems in your life. Circle one number.

$\begin{array}{lllcc}\text { not } & \text { some } & \text { a little } & \text { significant } & \text { very } \\ \text { at all } & \mathbf{2} & \mathbf{3} & \mathbf{4} & \mathbf{5}\end{array}$

\subsection{Operators Beliefs About the Code}

2.1 Please indicate the extent to which you agree or disagree with each of the following code related statements. Circle one .

strongly

disagree strongly

agree

2.1.1 The Johnstone Strait guidelines have helped to increase my business.
1
2
3
4
5

2.1.2 The rewards of following the guidelines have exceeded the potential costs for being in the business.
1
2
3
4
5

2.1.3 It is possible to put into practice all the guidelines outlined in the Code of Conduct.

1 
2.1.4 The guidelines treat all operators equally.

1

2

3

4

5

2.1.5. The guidelines are appropriate for the type of operation that I have 1 2 3 4

5

2.1.6. Voluntary compliance with the Code of Conduct is a more effective way of making the guidelines work than government enforcement.

1

2

3

4

5

2.1.7 Even though the code is voluntary, I comply with its guidelines in most situations.
1
2
3
4
5

2.1.8 Even though the code is voluntary, the tour operators that I have seen here, comply with the guidelines in most situations.

1

2

3
4

5

2.1.9 It is a tour operator's duty to follow all the guidelines, since they are meant to benefit the community's tourism industry.

1

2
3

4

5

2.1.10 It is a tour operator's duty to follow all the guidelines, since they are meant to benefit the health of the natural habitat.

1

2

3

4

5

2.1.11 Failing to comply with the guidelines is unacceptable.
1
2
3
4
5

2.1.12 Failing to comply with the guidelines is morally wrong. 1 2 3 4 5

\subsection{Code Effectiveness}

3.1 For each of the following items, please indicate(by circling one number) how important the code has been in:

\section{low} high

3.1.1 Encouraging a culture of communication between operators.

$$
\begin{array}{lllll}
1 & 2 & 3 & 4
\end{array}
$$

3.1.2 Elevating the moral conscience of the operators.

1
3 
3.1.3 Increasing common understanding among operators about self-imposed guidelines.
1
2
3
4
5

3.1.4 Encouraging discussion and new ideas to resolve problems. 1 2 3 4 5

3.1.5 Increasing the quality of experience for the clients.
1
2
3
4
5

3.1.6 Regulating behavior of operators around the whales.
1
2
3
4
5

3.1.7 Educating clients regarding the nature of responsible whale watching behavior.

12

2

3

4

5

3.1.8 Increasing the positive public image of the whale watching industry.
1
2
3
4
5

3.1.9 Encouraging the spread of a conservation message.
1
2
3
4
5

3.1.1.0 Influencing other boat traffic behavior around whales. 1

2

3

4

5

3.2. Please circle the degree to which you agree or disagree with these statements:

strongly

disagree

neutral

strongly

agree

3.2.1 The code of conduct is an effective voluntary approach to regulating human behavior in the whale watching environment.
1
2
3
4 5

3.2.2 At the time of its inception, developing the code of conduct helped to create a sense of collective solidarity amongst the operators.

$\begin{array}{llllll}1 & 2 & 3 & 4 & 5\end{array}$

3.2.3 The code of conduct helps to ensure a long-term commitment to sustaining the ecology of Johnstone Strait.

1

2

3

4

5 
3.2.4 The code of conduct confirms the intentions of tour operators to operate ethically and with appropriate sensitivity to the ecology of the area.
1
2
3
4
5

3.2.5 The code of conduct has helped me to feel more optimistic about the future of the whales and whale watching in Johnstone Strait. 1

2 3

4

5

3.3 Please provide any other comments on how the Johnstone Strait Code of Conduct might be more effective with respect to protecting the ecology of the area.

Thank you for your involvement in the process of evaluation of the Johnstone Strait Code of Conduct. Evaluation is important to the success of the Code of Conduct and ultimately to the preservation of the whales, natural habitats and the tourism industry in Johnstone Strait.

Please fax the completed survey to (604) 984-4993 by Nov. 12, 1996.

If you have any questions about the research, please do not hesitate to contact Greig Gjerdalen at (604) $984-2495$ or by fax $984-4993$

e-mail address- ggjerdal@sfu.ca 


\section{REFERENCES:}

ARA Consulting Group. 1991. Developing a Code of Ethics: British Columbia's Tourism Industry - Victoria: British Columbia Ministry of Development, Trade and Tourism.

Anderson, T. 1986. "Environmental ethics." In: Childress, J.F. and J. MacQuarrie (Eds.). The Westminster Dictionary of Christian Ethics. Philadelphia, PA.: The Westminster Press. pp. 196-198.

Arrow, K.J. 1979. "Business codes and economic efficiency." In: Beauchamp, T.L. and N.E. Bowie (Eds.) Ethical Theory and Business. Englewood Cliffs, N.J.: Prentice-Hall Inc. pp. 226-229.

Attfield, R. 1983. The Ethics of Environmental Concern. Oxford, England: Basil Blackwell Publisher Ltd.

Baxter, A. and Donoghue, M. 1995. Scientific Aspects of the Management of Whale and Dolphin Watching in New Zealand. Auckland: New Zealand Department of Conservation.

Bekker, P. 1991. Summary discussions of whale watching charter operators meeting in Port McNeil, B.C. Victoria, B.C.: Ministry of Small Business, Tourism and Culture.

Beckmann, L. 1994. "Marine Conservation in the Canadian Arctic." Northern Perspectioes, Canadian Arctic Resources Committee. Vol. 22, (2-3): 33-39. 
Beeler, T. and J. Wood. 1990. "Overcoming Environmental Obstacles." Ski Area Management, March, 4(3): 74.

Berkes, F. and M.T. Farvar. 1989. "Introduction and Overview", in F. Berkes, ed. Common Property Resources: Ecology and Community-Based Sustainable Development, London: Belhaven Press, pp. 1-17.

Berkes, F. and D. Feeny. 1990. "Paradigms Lost: changing views on the use of common property resources." Alternatioes 17(2): 12-18.

Bigg, M.A. 1983. "Photo-identification of Killer Whales." Whalewatcher, Spring.

Blood, D.A., I.B. MacAskie, and C.J. Low 1988. Robson Bight Ecological Reserve - Background Report. Prepared by D.A. Blood and Associates, for B.C. Ecological Reserves Program, Victoria: B.C. Ministry of Environment and Parks.

Briggs, D. 1991a. Usage of the rubbing beaches at RBMBER by whales and boats. Victoria, B.C.: Report prepared for the Ecological Reserves Program.

Briggs, D. 1991b. Impact On Killer Whales. Victoria, B.C.: British Columbia Ministry of Environment Lands and Parks.

Carnevale, P.J.D., D.G. Pruitt, and P.I. Carrington 1982. Effects of future dependence, liking and repeated requests for help on helping behavior, Albany NY. Social Psychology Quarterly (45): 1-9.

Creswell, J.W. 1994. Research Design: Qualitative And Quantitative 
Approaches. London: Sage Publications.

Culver, D. and R. Burke 1986. Unpublished paper, Suggested Guidelines For Johnstone Strait Whale Watching. Vancouver, B.C.

Darling, J.D. 1986. An Assessment Of The Effect Of Human Activities On The Killer Whales At Robson Bight Ecological Reserve. Vancouver, B.C.: West Coast Whale Research Foundation.

Dearden, P. and D. Duffus 1993. "Marine Parks: The Canadian Experience." Parks and Protected Areas in Canada: Planning and Management, ed. Dearden and Rollins. Toronto: Oxford University Press. pp 256-272.

de Calventi, I. 1995. The Dominican Experience in Humpback Whale Watching; Minimum Distances. Republic Dominicana: Fundacion Dominicana de Estudios Marinos, Santo Domingo.

Department of Fisheries and Oceans. 1987. Canada's Oceans: An Economic Overoiew And A Guide To Federal Government Activities. Ottawa: Supply and Services Canada.

Department of Fisheries and Oceans, Quebec Region. 1991. Guidelines To Small Craft Owners And Tour Boat Captains To Prevent Any Disturbance And Harassment Of Whales In The St. Lawrence River., Montreal, Quebec.

Donoghue, M. and, A. Baxter 1995. Scientific Aspects Of The Management Of Whale And Dolphin Watching In New Zealand. Auckland: Department Of Conservation. 
Duffus, D. and J. Ford 1995. "Public Participation in Management: The Case of Johnstone Strait Killer Whales." Unpublished paper presented to the workshop on the Scientific Aspects of Managing Whale Watching, Italy.

Environment Canada. 1986. National Marine Parks Policy. Ottawa: Supply and Services Canada.

Evens, P. 1995. “Some Thoughts About Regulating Whale Watching Activities." Unpublished paper presented to the workshop on the Scientific Aspects of Managing Whale Watching, Italy: Sea Watch Foundation, UK.

Fletcher, K. 1992. Corporate Culture and the Common Good: Creating a Vision of the Common Good Tending Corporate Culture. Unpublished thesis, Vancouver School of Theology.

Ford, J.K.B., G.M Ellis, and K.C. Balcomb. 1995. Killer Whales: The Natural History And Genealogy of Orcinus orca in British Columbia and Washington State. Vancouver: UBC Press.

Franklin, P. 1995. "The Evolving Management Program in Hervey Bay from the Perspective of a Permitted Operator." The Oceana Project. Rome Italy, Unpublished paper presented to the workshop on the Scientific Aspects of Managing Whale Watching, Italy.

Friedmann, J. 1987. Planning in the Public Domain: From Knowledge to Action. Princeton: University press.

Gjerdalen, Greig. 1993. Johnstone Strait Code of Conduct. Simon Fraser 
University, B.C.: Centre for Tourism Policy and Research.

Gramann, J.H. and G.A.Vander Stoep 1987. "Prosocial Behavior Theory and Natural Resource Protection: A Conceptual Synthesis." Journal of Environmental Management, 24: 247-257.

Grasmick, H.G. and R.J. Bursik, Jr. 1990. “Conscience, Significant Others and Rational Choice: Extending the Deterrence Model“ Law and Society Review, 24(3): 837-61.

Hardin, G. 1968. "The Tragedy of the Commons.." Science, 162, December: p. 1282.

Healy, R.G. 1994. "The 'Common Pool' Problem in Tourism Landscapes." Annals of Tourism Research, 21(3): 596-611.

Heberlein, T.A. 1972. "The Land Ethic Realized: Some Social Psychological Explanations For Changing Environmental Attitudes." Journal of Social Issues, 28: 79-87.

Henwood, W. 1990. Tour Operators and Marine Parks: The Case For A Positive Symbiotic Relationship. Discussion Paper. Vancouver, BC, Heritage Canada.

Heritage Canada/Parks Canada. 1994. Guiding Principles and Operational Policies. Ottawa: Supply and Services Canada.

Herzing, D. 1995. Working Paper for IFAW workshop, Rome Italy.

Hirschi, T. 1994. "A Control Theory of Delinquency." In Delos H. Kelly 
(ed.),Deoiant Behavior: A Text-Reader In The Sociology of Deviance. New York: St. Martin's Press.

Hoyt, E. 1990. Orca: The Whale Called Killer. Ontario: Camden House Printing.

Johnstone Strait Killer Whale Committee (Canada) 1991. Background Report. Victoria:British Columbia Ministry Of Environment, Lands and Parks, and federal Department of Fisheries and Oceans.

Kaza, S. 1988. "Community Involvement in Marine Protected Areas." Oceanus, 36: 75-81.

Maestro, M. 1992. Deviance and Social Control, edited by Linda B. Deutchmann, Toronto: University Press.

Mathieson, A. and G. Wall. 1982. Tourism: Economic, Physical and Social Impacts. New York: Longman.

Mischel, W. and H.N. Mischel 1976. "A Cognitive Social-Learning Approach to Morality and Self-Regulation." In Moral Development and Behavior, T. Lickona, Editors, New York: Holt, Reinhart \& Winston, pp. 84-107.

Morton, Robert. 1993. "Environmental Leadership: The Way To Compliance And Beyond." Journal of Environmental Regulation 3(1): 33-40.

Nash, R.F. 1989. “The Rights of Nature." A History of Environmental Ethics. Madison, Wisconsin: University of Wisconsin Press. 
National Marine Fisheries Service. 1985. Northwest Region Whale Watching Guidelines. Seattle:, NorthWest region.

National Marine Fisheries Service. 1987. Federal Regulations On Approaching Humpback Whales In Hawaii.

Ostrom, Elinor. 1990. Governing the Commons: The Evolution of Institutions for Collective Action.. Cambridge: University Press.

Paternoster, R.L., E. Saltzman, G.P. Waldo and T.G. Chiricos 1983. “Perceived Risk and Social Control: Do Sanctions Really Deter?" Law and Society Review, 17(3): 457-79.

Pinkerton, Evelyn. 1993. "Local Fisheries co-management: A Review of International Experience and Their Implications for Salmon Management in British Columbia." Discussion Paper. University of British Columbia: School of Community and Regional Planning.

Reece, P. 1996. "Watching Whales Watching Us". The Vancouver Courier. 87(91): 3-7

Rolston III, H. 1988. "Environmental Ethics." Duties to and Values in the Natural World. Philadelphia: Temple University Press.

Sears, R. 1995. Whale Watching in Canadian Waters with Emphasis on the St. Lawrence Estuary and Gulf. Mingam Island Cetacean Study, Inc. Unpublished paper presented to the workshop on the Scientific Aspects of Managing Whale Watching, Italy. 
Sirakaya, E. 1995. Voluntary Compliance of Ecotour Operations With Ecotourism Guidelines. Clemson University Dissertation. Clemson, S.C.: Clemson University Press.

Todd, S. and P.W. Williams, 1996. "From white to green: A proposed environmental management system for ski areas,: Journal of Sustainable Tourism, 4(3): 147-173.

United Nations Environment Programme, Industry and Environment 1993. Environmental Codes of Conduct. Paris, France.

United States National Park Service. 1990. Glacier Bay National Park Whale Watching Regulations.

VanderZwaag, D. and C. Lamson. 1986. "Northern Decision Making: A Drifting Net In A Restless Sea." ed. C. Lamson and D. VanderZwaag In Transit Management in the Northwest Passage,. Cambridge: Cambridge University Press.

Viswanathan, K.K. 1992. Deterrence and Voluntary Compliance With The Zoning Regulation in the Malaysian Fishery. Unpublished dissertation, University of Rhode Island.

Williams, P.W. 1992 "Environmental Business Practice: Ethical Codes for Tourism." Arizona Hospitality Trends, 7(1), Winter: 8-11.

Wiley, D. 1995. “Can Education Programs Effectively Control Harassment By Recreational Boats?" IWC Whale Adoption Project. Unpublished paper presented to the workshop on the Scientific Aspects of Managing Whale Watching, Italy. 
Winkler, E.R. and J.R. Coombs, 1993. Applied Ethics: A Reader Massachusetts: Blackwell Publishers, 416-424.

Wursig, B. 1995. Dolphin Watching and swim-with dolphin tours. Unpublished paper presented to the workshop on the scientific aspects of Managing Whale Watching, Italy.

Yin, R.K. 1993. Applications of Case Study Research. Applied Social Research Methods Series, London: SAGE Publications, Vol 34.

\section{PERSONAL COMMUNICATIONS:}

Arcese, D. July, 1996. Owner operator of Northern Lights Expeditions, Vancouver, B.C.

Borrowman, J. November, 1996. Owner/operator Stubbs Island Whale Watching Charters. Telegraph Cove, B.C.

Ford, J. September 1996. Marine mammal curator, Vancouver public aquarium, Vancouver, B.C.

Gjerdalen, K. 1997. Mariner. Inside Passage, B.C.

Lochbaum, E. 1993. DFO, Nanaimo, B.C. 
Lubar, J. 1993. DFO, Vancouver, BC.

Mackay, B. 1992. Stubbs Island Charters, Telegraph Cove, B.C.

Taylor, R. 1994. JSKWC member and environmental consultant, Vancouver, B.C. 

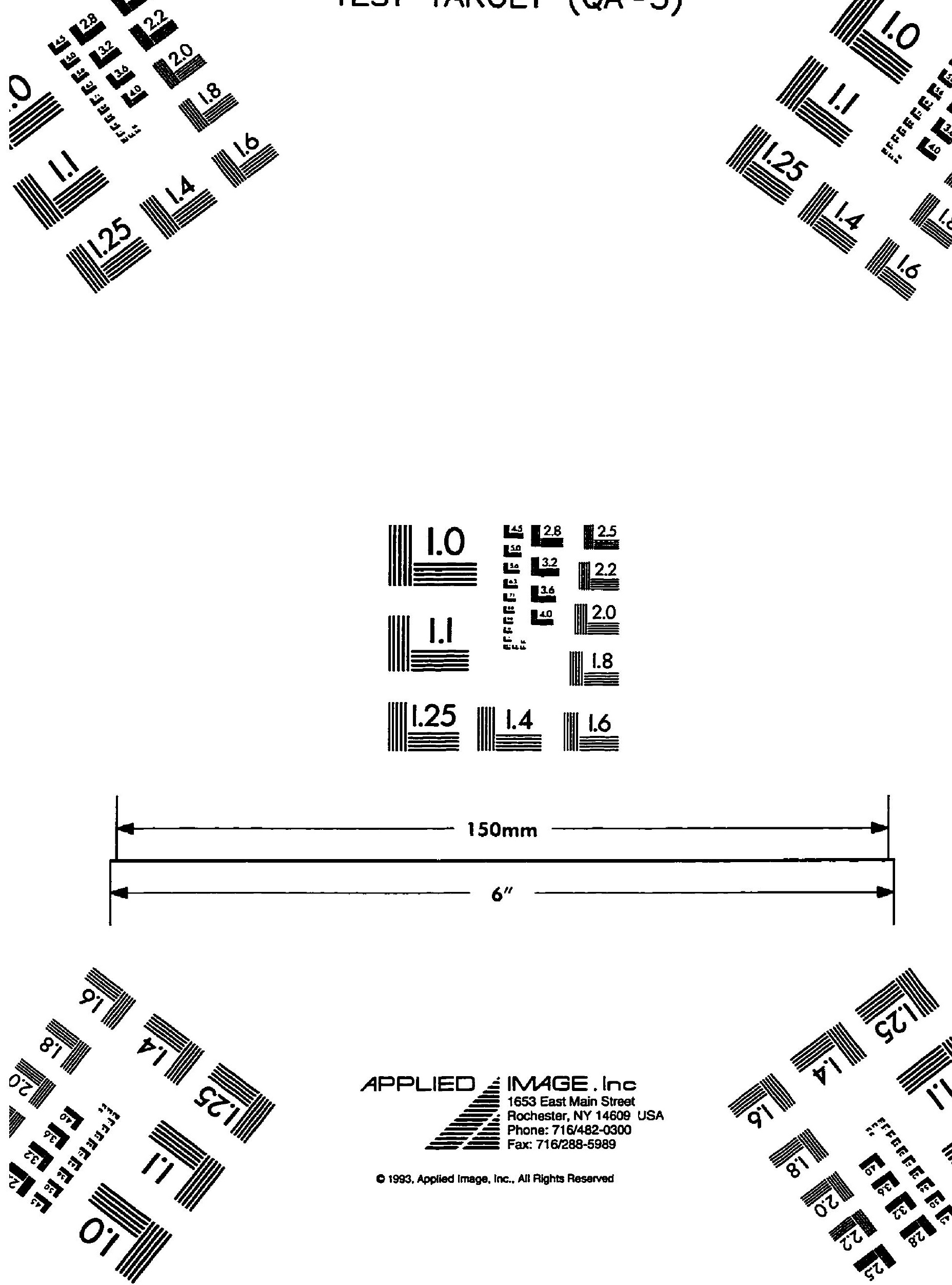

APPLIED ڤIMAGE. InC 1653 East Main Street

Rochester, NY 14609 USA

Phone: 716/482-0300

Fax: 716/288-5989

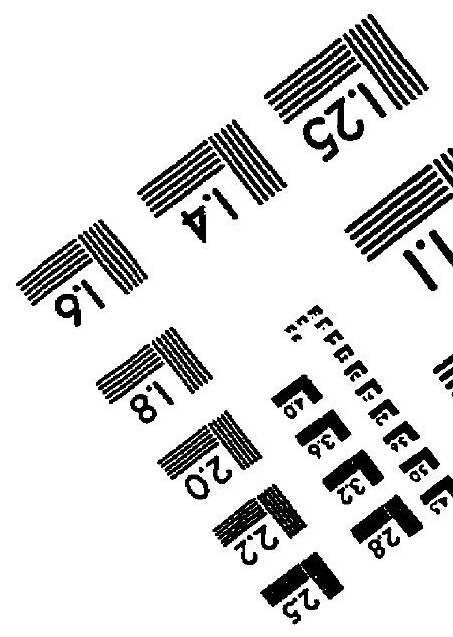

